\title{
The Demand for Liquid Assets, Corporate Saving, and International Capital Flows*
}

\author{
Philippe Bacchetta \\ University of Lausanne \\ Swiss Finance Institute \\ CEPR
}

\author{
Kenza Benhima \\ University of Lausanne \\ CEPR
}

September 2014

\begin{abstract}
The recent period of capital outflows from emerging economies has coincided with an increase in their corporate saving. In this paper, we model corporate saving as a demand for liquid assets by credit-constrained firms in a dynamic open-economy macroeconomic model. We find that the implications of this model are very different from standard models, because the demand for foreign bonds is a complement to domestic investment rather than a substitute. We show that this complementarity is at work when an emerging economy is on its convergence path or when it has a higher TFP growth rate. This framework is consistent with a number of stylized facts found in high-growth, high-investment emerging economies.
\end{abstract}

*We would like to thank six anonymous referees, Nicolas Coeurdacier, Michael Devereux, Marcel Fratzscher, Olivier Jeanne, Robert Kollman, and several seminar and conference participants for comments. We gratefully acknowledge financial support from the National Centre of Competence in Research "Financial Valuation and Risk Management" (NCCR FINRISK). Bacchetta also acknowledges support from the ERC Advanced Grant \#269573. 


\section{Introduction}

The increase in foreign asset holdings by emerging Asia, mainly in the form of liquid assets, has been a major feature of the recent episode of global imbalances. This increase in net saving has typically been associated with household saving. However, the episode of global imbalances also coincides with a sharp increase in corporate saving in emerging Asia. Figure 1 shows the precrisis evolution of corporate saving rates for a subset of Asian countries. ${ }^{1}$ The average corporate saving rate dramatically increased since 1998. This evolution contrasts with a much smaller increase in other countries. Using the same data, the left panel of Figure 2 shows the increase in the corporate saving rate over the pre-crisis decade 1998-2007. This rate increased substantially more for emerging Asian countries (8.1\%) than for other emerging countries (4.0\%) or for G-7 countries (1.3\%). ${ }^{2}$ The middle panel of Figure 2 shows that the investment rate also increased significantly more in emerging Asia. However,

1. These countries are China, India, South Korea, Philippines and Thailand. The other countries in Figure 1 include 28 developed and emerging countries for which UN corporate saving data is available. Taiwan is included in the Emerging Asia group in Figure 2 and not in Figure 1 because of data availability for corporate saving. See Appendix A for data description. See also Karabarbounis and Neiman (2012) for a recent estimate of global corporate saving and a description of its measurement.

2. These numbers correspond to GDP weighted averages. If we consider instead the simple average (thus giving less weight to China) the increase in corporate saving in emerging Asian countries was $6.7 \%$. 
investment increased less than corporate saving, which is an indication that firms increased their non-productive asset holdings. This implies that corporate saving has contributed to the high current account surpluses observed in these countries during the period. Figure 2 also shows that emerging Asian countries experienced an exceptionally high average growth rate over the 1998-2007 period.

The objective of this paper is to analyze the relationship between corporate saving and capital flows in fast-growing emerging economies. We model explicitly the demand for liquid assets by firms in an infinite horizon economy with a low level of financial development in the form of strong credit constraints. We show that binding constraints imply a complementarity between foreign bonds and domestic investment, which is in sharp contrast with standard intertemporal models where capital and foreign bonds are substitutes. Consider for example an increase in domestic productivity growth. In standard models, investment increases while foreign bonds decline through external borrowing. This tends to imply a current account deficit. In contrast, a model with liquidity demand implies an increase in foreign bonds holdings following a positive productivity shock. Importantly, strong growth makes the credit constraint active, which generates the complementarity. This means that stronger growth may lead to a current account surplus.

The model's implications are consistent with various features related to the recent episode of capital flowing from emerging Asia to the U.S. First, the 
recent period coincided with episodes of high growth and increasing investment levels in Asia, as illustrated in Figure 2. Second, emerging Asia experienced increasing net foreign asset positions and high current account surpluses. ${ }^{3}$ Episodes of growth acceleration that are accompanied by net capital outflows have also been documented by Sandri (2014). This feature is related to the "allocation puzzle" described by Gourinchas and Jeanne (2013), whereby the fastest growing economies tend to export capital instead of attracting it. Our model is consistent with that fact as the complementarity between investment and bonds emerges only for fast-growing countries.

The demand for liquid assets comes from infinitely lived creditconstrained entrepreneurs who have investment projects that last two periods. Entrepreneurs need to install their capital one period before producing, so capital is a long-term asset while bonds are short-term assets. In the period where entrepreneurs install their capital, they anticipate a need for funds (working capital) to operate their firms, e.g., to hire labor. If entrepreneurs are credit-constrained for their future working capital, they will need to save in liquid bonds at the same time as they invest in capital. Since bonds are used to finance inputs that are imperfect substitutes to capital, this creates a complementarity between capital and liquid assets. In contrast, if entrepreneurs are unconstrained, they can borrow their working capital and have no need

3. The average GDP-weighted current account surplus was $3.0 \%$ of GDP over the 19982007 period. It peaked at $6.2 \%$ in 2007 . 
for liquidity. This liquidity motive is generated by a production structure, with time-to-build and working capital, that can be naturally incorporated in a dynamic macroeconomic model. ${ }^{4}$ We assume that entrepreneurs have an investment project every other period and that at each period half the entrepreneurs have a new project. We consider both a small open economy and an asymmetric two-country framework composed of an industrial country and an emerging country. We show that, due to lower financial development, the emerging country has a demand for liquidity that can generate net capital outflows.

Our framework features an overlapping structure where firms alternate between investment periods where they are cash-rich and production periods where they are cash-poor. This is a stylized way to represent fluctuations in corporate liquidity needs. This approach, borrowed from Woodford (1990), helps derive analytical results because it reduces the dimensionality of the problem by limiting heterogeneity, as the only source of heterogeneity is the existence of two groups of entrepreneurs who start projects at alternating dates. Whereas in Woodford (1990) entrepreneurs receive high productivity projects on alternating dates, our entrepreneurs invest and produce at alternating dates.

4. The assumptions of time-to-build and working capital are often made in macroeconomic models. For example, see Gilchrist and Williams (2000) for multi-period investment projects and Christiano et al. (2011) for working capital to pay for the wage bill. 
The income stream is deterministic but it fluctuates, which generates additional saving when agents face financial constraints, even in the absence of risk.

While our model is built to study macroeconomic questions which have hardly been addressed in the literature on liquidity, it shares many features with previous work in corporate finance. In particular, as in Holmstrom and Tirole (2001), the lack of pledgeability of future output is crucial to generate a demand for liquid assets. ${ }^{5}$ The empirical literature has also documented the link between the demand for liquid assets and financial development. Almeida et al. (2004) show that more constrained firms hold more cash out of their cash flow. Khurana et al. (2006) find that the sensitivity of cash holdings to cash flow is higher in less financially developed economies. ${ }^{6} 7$

5. Most of the literature following Holmstrom and Tirole (2001) is cast in a microeconomic setup with two or three periods. However, Aghion et al. (2010) and Kyiotaki and Moore (2012) present dynamic macroeconomic models where entrepreneurs hoard in the perspective of future liquidity shocks.

6. This also implies a strong correlation between liquidity and corporate saving in less financially developed countries. For example, McLean (2011) shows that a substantial proportion of cash increases of US firms is financed by share issuance, which does not affect firms' saving.

7. While we follow the relatively mainstream literature on corporate liquidity there may be additional causes for high corporate saving in less economically developed countries. For example, firm managers may value liquid assets when there is a threat of expropriation. 
Our contribution is also related to a growing literature introducing credit market imperfections in open economy models. ${ }^{8}$ In particular, Song et al. (2011) model a capital outflow with firm heterogeneity specific to the Chinese economy. Similarly to our framework, a key feature is the interaction of strong productivity growth and tight credit constraints. ${ }^{9}$ However, their focus is on growth and they do not introduce a demand for liquid assets. Another related paper is Buera and Shin (2010) who show that removing distortions in goods production can both increase TFP and generate capital outflows. One of the mechanisms leading to a capital outflow is similar to ours, in the sense that entrepreneurs facing productivity growth and credit constraints increase their saving. Coeurdacier et al. (2012) also model capital outflows in growing emerging economies, but they focus on credit-constrained consumers.

The recent literature has proposed two main explanations for the net capital outflows from emerging markets. First, emerging markets have a limited supply of financial assets (e.g., Dooley et al., 2005, Matsuyama, 2007, Ju and Wei, 2006, 2010, Caballero et al., 2008, and Aguiar and Amador, 2011). Second,

8. Earlier contributions include Aghion et al. (2004) and Gertler and Rogoff (1990).

9. Consistent with this persective, using Chinese data, Huang (2011) finds that cash holdings are larger for private firms that are typically more credit-constrained. Bayoumi et al. (2012) argue that the behavior of Chinese firms is not different from firms in other countries. However, they focus on state-owned enterprises that appear to have a different behavior (Song et al., 2011). 
net capital outflows result from precautionary saving due to idiosyncratic risk (e.g., Mendoza et al., 2009, Sandri, 2014, Angeletos and Panousi, 2011, Benhima, 2013). However, the fact that recent imbalances involve liquid assets and corporate saving has only received limited attention. Moreover, growth is usually associated with capital inflows in the short run, even in precautionary saving models that feature imperfect asset substitutability, which is counterfactual in the case of emerging Asia. The reason is that bonds and capital are still substitutes: an increase in domestic productivity still pushes the domestic return on capital upward, which generates capital inflows. ${ }^{10}$ In contrast, with a liquidity need high productivity will be associated with high investment and a net capital outflow. To distinguish from the impact of asset riskiness, we consider a model without uncertainty and abstract from business cycle issues. ${ }^{11}$

10. In Mendoza et al. (2009) and especially Mendoza et al. (2007), excess saving generated by risk is diverted from domestic capital to foreign assets which leads to a decrease in investment. While Benhima (2013) shows that with investment risk growth is associated with capital outflows in the long run, Angeletos and Panousi (2011) show that financial liberalization still coincide with a decrease in investment on impact. Closer to our approach, Sandri (2014) generates a positive comovement between growth and capital outflows under risky entrepreneurship. But this comovement results only from a change in the structure of the population, whereas our mechanism accommodates any source of growth.

11. The presence of uncertainty introduces additional mechanisms, such as precautionary saving, affecting capital flows. The main issue is that entrepreneurs might save enough to become unconstrained, which would make our mechanism irrelevant. However, if 
To better explain the model's mechanism we first examine the behavior of entrepreneurs in partial equilibrium when they are either constrained or unconstrained. We show that credit-constrained entrepreneurs have a demand for liquidity and examine the properties of this demand. Then we incorporate these entrepreneurs in a dynamic small open economy and examine its dynamics and steady state. In a growing economy, financial constraints increase saving by cash-rich entrepreneurs and reduce the supply of assets issued by cash-poor entrepreneurs. We extend the analysis to a two-country general equilibrium model, assuming that entrepreneurs in one country, the Emerging country, are constrained and those in the other country, the Industrial country, are unconstrained. We derive analytical results in a simple benchmark case and then provide numerical results in more general cases.

We show that the demand for liquid assets arises whenever the emerging economy is credit-constrained. When the emerging country has the same rate of impatience as the rest of the world, it is not constrained in the steady state. But we show that credit constraints still emerge in three distinct situations: i) in its convergence path towards its unconstrained steady state; ii) in a steady state where TFP growth is permanently higher than in other countries; iii) with temporary increases in TFP growth. While the first two situations can

growth is sufficiently strong entrepreneurs become more impatient, which counteracts the precautionary saving motive, and the basic mechanism described in this paper would still be at work. 
be studied analytically, we use numerical simulations to examine temporary shocks. Importantly, we do not assume that the emerging country is more impatient by imposing different preferences (different discount factors). The emerging country is credit-constrained because its higher growth rate makes it endogenously more impatient. We find that in all these situations, the model matches the various facts mentioned above. Indeed, when a country experiences high growth, it becomes constrained which makes capital and foreign assets complementary. This generates a positive correlation between growth, investment and capital outflows.

Although these results are derived in a stylized framework, we consider several extensions to show that the basic mechanism holds in a wider context. First, we show that the demand for liquid assets can coincide with FDI inflows, thereby generating two-way capital flows. Second, we examine the impact of a capital account liberalization. Third, we argue that the demand for liquid assets by entrepreneurs can be consistent with an accumulation of reserves by the central bank.

In Section 2 we describe the mechanism leading to the demand for liquidity by credit-constrained entrepreneurs. Section 3 presents the small open economy model and Section 4 describes the two-country analysis. Section 5 examines various extensions. Section 6 concludes. 


\section{Entrepreneurs and the Demand for Liquidity}

We first consider entrepreneurs in a partial equilibrium setup. This allows us to clearly understand the mechanism behind the demand for liquid assets. There are basically three ingredients in the model that are necessary to generate a demand for liquidity. First, a portion of the wage bill has to be paid before output is available to entrepreneurs. This generates a need for funds. The second assumption is that entrepreneurs face credit constraints. This implies that entrepreneurs are not always able to borrow all the funds needed to hire labor for production. Third, entrepreneurs decide simultaneously on their levels of capital and bonds. Combining these three ingredients implies that, when they invest in capital, entrepreneurs need to keep liquid assets. The fact that liquid assets are used to finance a production factor (here, labor) that is imperfectly substitutable with capital generates a complementarity between these assets and capital.

A simple way to introduce the third ingredient is to assume a time-tobuild technology, in the form of two-period projects, so that capital and bonds are determined in advance. An alternative, often considered in the literature, would be to consider a model with subperiods. ${ }^{12}$ However, using subperiods implicitly implies a fluctuating aggregate demand for liquidity

12. E.g., see Christiano et al. (2011). Bacchetta et al. (2014) extend the structure of Christiano and Eichenbaum (1995) to allow for a demand for liquidity. 
across subperiods. Instead, assuming overlapping two-period projects allows us to aggregate the net demand for bonds, as will become clear in Section 3 .

In this section, we focus on the demand for liquidity by entrepreneurs. In particular, we study how they allocate their saving between capital and liquidity. We first describe the optimal behavior of entrepreneurs in a general setup. We then focus on a benchmark case that allows us to derive analytical results on the demand for liquidity.

\subsection{The production process}

Entrepreneurs are infinitely lived and maximize the present value of their utility. They have two-period production projects as it takes one period to install capital before producing. An entrepreneur starting a project at time $t$ installs $K_{t+1}$. At $t+1$, he hires labor $l_{t+1}$ to produce $Y_{t+1}=K_{t+1}^{\alpha}\left(A_{t+1} l_{t+1}\right)^{1-\alpha}$,

where $A_{t}$ measures productivity, and pays a fraction $\kappa$ of wages $w_{t+1} l_{t+1}$. This production is available only at $t+2$. At $t+2$, the entrepreneur pays the remaining wages and starts a new project. He is left with a capital stock of $(1-\delta) K_{t+1}$, where $\delta$ is the depreciation rate. The entrepreneur also consumes $c_{t}$ each period and can borrow or lend short-term bonds $B_{t}$ with a gross interest rate $r_{t}$.

In this setup, working capital in the form of early payment of wages (high $\kappa)$ and credit constraints interact to generate a demand for liquidity. At time $t$, entrepreneurs can use part of the proceeds from previous production to invest 
$K_{t+1}-(1-\delta) K_{t-1}$ and pay the remaining wages at $t$. At $t+1$, however, they have no income to pay $\kappa w_{t+1} l_{t+1}$ for workers. An entrepreneur has an incentive to borrow $-B_{t+2}$, but if he is credit-constrained he will not be able to borrow the desired amount to pay for the wage bill. He will therefore have a demand for liquidity at time $t$ in the form of a positive demand for bonds, $B_{t+1}$. On the other hand, when the entrepreneur is unconstrained, there is no need for liquidity at time $t$.

\subsection{Optimal Behavior}

Entrepreneurs maximize:

$$
\sum_{s=0}^{\infty} \beta^{s} \ln \left(c_{t+s}\right)
$$

Consider an entrepreneur who invests every other period, starting at time $t$

. Denote by $W_{t}$ his initial income at time $t$. It is made of the output from production initiated at date $t-2, Y_{t-1}=K_{t-1}^{\alpha}\left(A_{t-1} l_{t-1}\right)^{1-\alpha}$, of the remaining capital stock $(1-\delta) K_{t-1}$ and of the return from bond holdings, $r_{t} B_{t}$. Hence, $W_{t}=Y_{t-1}+(1-\delta) K_{t-1}+r_{t} B_{t}$. His budget constraints at $t$ and $t+1$ are:

$$
\begin{gathered}
W_{t}=c_{t}+(1-\kappa) w_{t-1} l_{t-1}+K_{t+1}+B_{t+1} \\
r_{t+1} B_{t+1}=c_{t+1}+\kappa w_{t+1} l_{t+1}+B_{t+2}
\end{gathered}
$$


The income of the entrepreneur at date $t$ is allocated to consumption, $c_{t+1}$, the remaining wages $(1-\kappa) w_{t-1} l_{t-1}$, investment in a new project, $K_{t+1}$, and bond holdings $B_{t+1}$. In the following period, at $t+1$, the only income is the bond return, $r_{t+1} B_{t+1}$. This has to pay for consumption $c_{t+1}$ and part of the wage bill $\kappa w_{t+1} l_{t+1}$. Typically the entrepreneur will borrow, so that at the optimum $B_{t+2} \leq 0$.

The entrepreneur might face a credit constraint at date $t+1$. Due to standard moral hazard arguments, a fraction $0 \leq \varphi \leq 1$ of capital has to be used as collateral for bond repayments: ${ }^{13}$

$$
r_{t+2} B_{t+2} \geq-\varphi K_{t+1}
$$

Let $\lambda_{t+1}$ denote the multiplier associated with this constraint. The entrepreneur's program yields the following first-order conditions:

$$
\begin{gathered}
\alpha\left(\frac{K_{t+1}}{A_{t+1} l_{t+1}}\right)^{\alpha-1}+1-\delta=r_{t+1} r_{t+2}\left(1+\frac{\lambda_{t+1} c_{t+2}}{\beta}\left(1-\frac{\varphi}{r_{t+1} r_{t+2}}\right)\right) \\
(1-\alpha)\left(\frac{K_{t+1}}{A_{t+1} l_{t+1}}\right)^{\alpha}=\frac{w_{t+1}}{A_{t+1}}\left[\kappa r_{t+2}\left(1+\frac{\lambda_{t+1} c_{t+2}}{\beta}\right)+(1-\kappa)\right] \\
\frac{c_{t+1}}{c_{t}}=\beta r_{t+1}
\end{gathered}
$$

13. There could be a similar constraint at date $t$, but one can show that it is never binding, precisely because of the demand for liquidity. 


$$
\frac{c_{t+2}}{c_{t+1}}=\beta r_{t+2}\left(1+\frac{\lambda_{t+1} c_{t+2}}{\beta}\right)
$$

The credit constraint (4) introduces three wedges in the optimal decisions. First, from Equation (5), when $\lambda_{t+1}=0$, the marginal return of capital invested at $t$ should be equal to the return of one unit invested over two periods in the bond, $r_{t+1} r_{t+2}$, as capital is immobile for two periods. But when $\lambda_{t+1}>0$, the constraint is binding at $t+1$, which implies that the entrepreneur is unable to finance the wage bill associated with the first-best capital stock. This creates a wedge between the return on capital and the bond return. Moreover, this wedge is decreasing in $\varphi / r_{t+1} r_{t+2}$, which is the relative liquidity value of capital as compared to the bond. Second, from Equation (6), when $\lambda_{t+1}=0$, the marginal return of labor should be equal to its cost, which is given by the wage rate multiplied by $\kappa r_{t+2}+(1-\kappa)$. The cost of the fraction $\kappa$ of wages that is paid in advance is upgraded by the interest rate because it generates an opportunity cost to the entrepreneur. When $\lambda_{t+1}>0$, the entrepreneur has exhausted his financing capacities before hiring the first-best level of labor, which creates a wedge between the marginal productivity of labor and the wage. Finally, when $\lambda_{t+1}>0$, it is more difficult to transfer consumption between period $t+1$ and $t+2$ : there are excess saving at $t+1$, as Equation (8) suggests. 


\subsection{A Benchmark Case}

To derive simple analytical results for the constrained entrepreneur $\left(\lambda_{t+1}>\right.$ 0), we consider a benchmark where we make three specific assumptions: i) entrepreneurs cannot borrow: $\varphi=0$; ii) wages have to be paid entirely in advance: $\kappa=1$; iii) capital depreciates fully: $\delta=1$. We examine the implications of relaxing these assumptions in Section 3.

With $\log$ utility, it can be shown that an entrepreneur who invests at $t$ consumes a fixed fraction of his revenue:

$$
c_{t}=(1-\beta) W_{t}
$$

Using the Euler equation (7) at $t$, we get the following rule for consumption at $t+1:$

$$
c_{t+1}=\beta(1-\beta) r_{t+1} W_{t}
$$

From (2) and (9), total saving at $t$ is:

$$
S_{t+1}=B_{t+1}+K_{t+1}=\beta W_{t}
$$

Equation (11) states that total saving at $t$ is a constant fraction of total revenues. This equation is used to derive $B_{t+1}$. In the constrained case, we 
need to determine jointly $K_{t+1}$ and $B_{t+1}$. In the unconstrained case, $K_{t+1}$ is first found independently of $B_{t+1}$ and then $B_{t+1}$ can be derived from (11). ${ }^{14}$

To determine whether entrepreneurs are constrained or not, it is useful to look at labor market conditions. Entrepreneurs are constrained $\left(\lambda_{t+1}>0\right)$ whenever the market wage is lower than the first best wage. Define $\tilde{w}_{t}=w_{t} / A_{t}$ the wage normalized by TFP and $\widehat{w}\left(r_{t+1}, r_{t+2}\right)=(1-\alpha)\left[\alpha^{\alpha} /\left(r_{t+1}^{\alpha} r_{t+2}\right)\right]^{\frac{1}{1-\alpha}}$ its first-best level. Entrepreneurs are constrained when $\tilde{w}_{t+1}<\widehat{w}_{t+1} \cdot{ }^{15}$ In that case, the entrepreneur could make infinite profits by increasing the production scale, but is prevented by the binding credit constraint. If $\tilde{w}_{t+1}=\widehat{w}_{t+1}$, the production scale is undetermined, because of constant returns to scale. There is no reason for the entrepreneur to be constrained in that case.

\subsection{The Demand for Liquidity from Constrained Entrepreneurs}

When the constraint at $t+1$ is binding, the availability of funds to finance the wage bill at $t+1$ is limited. The fraction of saving allocated to liquidity $B_{t+1}$

14. Notice that an increase in corporate saving implies an accumulation of liquidity only to the extent that it increases more than investment. Figure 2 shows that this is the case for emerging Asian countries.

15. This can be seen by combining first-order conditions (5) and (6) in the benchmark case, which yields:

$$
\tilde{w}_{t+1}\left(1+\frac{\lambda_{t+1} c_{t+2}}{\beta}\right)^{1-\alpha}=\widehat{w}\left(r_{t+1}, r_{t+2}\right)
$$


therefore depends on the liquidity needs at $t+1, w_{t+1} l_{t+1}$. These needs are related to the amount of capital $K_{t+1}$ invested at $t$, since $K_{t+1}$ and $l_{t+1}$ are imperfect substitutes.

Since $\varphi=0$, the first-order conditions (5) and (6) give a straightforward relationship between the liquidity needs $w_{t+1} l_{t+1}$ and capital $K_{t+1}$ :

$$
w_{t+1} l_{t+1}=\frac{1-\alpha}{\alpha} r_{t+1} K_{t+1}
$$

To determine $K_{t+1}$ we use (3), (10), (11) with (12) to get:

$$
K_{t+1}=\alpha \beta^{2} W_{t}
$$

Replacing in (11), we obtain:

$$
B_{t+1}=\beta(1-\alpha \beta) W_{t}
$$

Moreover, since $\varphi=0, B_{t+2}=0$.

The key implication of (13) and (14) is that the ratio between $B_{t+1}$ and $K_{t+1}$ is constant:

$$
\frac{B_{t+1}}{K_{t+1}}=\frac{1-\alpha \beta}{\alpha \beta}
$$

This implies that, contrary to standard models, capital and bonds are complements, because bonds are needed to finance the wage bill, which is 
proportional to capital. Indeed, the bond-capital ratio is decreasing in $\alpha$, the share of capital in the value added. The higher $\alpha$, the lower the amount of bonds needed to finance labor. An important consequence of this result is that growth in $K$ will naturally generate growth in $B$, leading to so-called "global imbalances".

The complementarity between liquidity and capital is in sharp contrast with the case where entrepreneurs are unconstrained. In the unconstrained case, capital and the demand for bonds are substitutes. Indeed, capital is determined by (5), and the demand for bonds is determined by the amount of saving that is not used for capital, just as in standard models.

\section{A Small Open Economy Model}

The entrepreneurs described above are incorporated into a small open economy model. There are two groups of entrepreneurs, with each group starting a project at alternating dates, as well as consumers-workers who supply labor to entrepreneurs. Entrepreneurs can lend or borrow at the world interest rate $r_{t}$. We assume that the rest of the world has a constant productivity growth $g^{*}$, a discount factor $\beta^{*}$, and no financial frictions. Hence the world interest rate is constant at $r^{*}=\left(1+g^{*}\right) / \beta^{*}$.

For convenience, we assume that workers are hand-to-mouth, i.e., consume all their income: $c_{t}^{w}=w_{t} l_{t}$. This can be justified by assuming that workers face a no-borrowing constraint. The Technical Appendix shows that this is the case 
when workers have no initial wealth and face a growing income stream. Since the income stream of workers is growing in all the experiments we conduct, this hand-to-mouth assumption is without loss of generality, as long as it is admitted that workers have a limited access to financial markets. An important consequence of this assumption is that workers cannot supply liquid assets to entrepreneurs, so foreign financial markets are the only source of liquidity.

We assume that the small open economy is defined by the benchmark, that is by $\varphi=0, \kappa=1$ and $\delta=1$. The discount factor $\beta$ is the same as in the rest of the world, $\beta=\beta^{*}$, and the productivity growth rate is $g_{t}=A_{t} / A_{t-1}-1$. After describing entrepreneurs and the labor market in this economy, we describe the dynamics and the steady state for a constant growth rate $g$. Then, we examine examples of transitory increases in growth. It will be convenient to normalize the variables by $A_{t}$ and denote $\tilde{X}_{t}=X_{t} / A_{t}$.

\subsection{Two Groups of Entrepreneurs}

Each entrepreneur has access to a project every other period. There are two groups of entrepreneurs, each with mass one, with overlapping projects. One group of entrepreneurs gets a project in odd periods, while the other group gets a project in even periods. The analysis of a single entrepreneur, described in the previous section, can be easily extended by slightly changing the notation. Denote by $\tilde{B}_{t+1}^{1}$ and $\tilde{B}_{t+1}^{2}$ the demands for bonds of entrepreneurs who are respectively in their investment and in their production periods (i.e., 
entrepreneurs who have started their project at time $t$ and at time $t+1)$. Then, from (14) we have:

$$
\begin{aligned}
& \tilde{B}_{t+1}^{1}=\frac{\beta(1-\alpha \beta)}{1+g_{t+1}} \tilde{W}_{t} \\
& \tilde{B}_{t+1}^{2}=0
\end{aligned}
$$

and the total demand for bonds at time $t$ is: $\tilde{B}_{t+1}=\tilde{B}_{t+1}^{1}+\tilde{B}_{t+1}^{2}$.

The two groups of entrepreneurs never interact on the domestic labor market, as they only hire labor in their production period. Since the world interest rate $r^{*}$ is given, the dynamics of the two groups can be studied independently from each other. As entrepreneurs are identical within a given category, the behavior of the aggregate economy is obtained simply by summing their policy functions.

\subsection{Labor Market}

3.2.1. Labor demand. In the previous section we showed that entrepreneurs are constrained when $\tilde{w}_{t+1}<\widehat{w}\left(r^{*}, r^{*}\right)=(1-\alpha) \alpha^{\frac{\alpha}{1-\alpha}} / r^{* \frac{1+\alpha}{1-\alpha}}$. We simply denote $\widehat{w}\left(r^{*}, r^{*}\right)$ by $\widehat{w}$. In this case, labor demand is determined by entrepreneurs' wealth as credit constraints are binding. In the unconstrained case, labor demand is undetermined as long as entrepreneurs have enough funds. The maximum labor demand in this case depends on entrepreneurs' wealth and 
can be written as follows:

$$
\bar{l}_{t+1}=\bar{l}\left(\tilde{W}_{t}, \tilde{w}_{t+1}, g_{t}\right)=\frac{(1-\alpha) r^{*} \beta^{2} \tilde{W}_{t}}{\left(1+g_{t+1}\right) \tilde{w}_{t+1}}
$$

Labor demand is then described as follows:

$$
\begin{array}{ll}
l_{t+1} \in\left(0, \bar{l}_{t+1}\right) & \text { if } \tilde{w}_{t+1}=\widehat{w} \\
l_{t+1}=\bar{l}_{t+1} & \text { if } \tilde{w}_{t+1}<\widehat{w}
\end{array}
$$

3.2.2. Labor supply and labor market equilibrium. Labor is supplied domestically by a continuum of hand-to-mouth workers of mass one who do not have access to the production technology. We assume that workers supply inelastically 1 unit of labor so that $l_{t}=1$. There are two different situations for labor market equilibrium. If the aggregate wealth $\tilde{W}_{t}$ is large enough so that $\bar{l}_{t+1} \geq 1$, then firms are able to hire all the workforce at its marginal productivity. In that case $l_{t+1}=1, \tilde{w}_{t+1}=\widehat{w}$ and firms are unconstrained. Otherwise, $\bar{l}_{t+1}<1, \tilde{w}_{t+1}<\widehat{w}$ and firms are constrained.

\subsection{Dynamics and Balanced Growth Path}

We now examine the dynamics and the balanced growth path of this economy for a constant growth rate $g$. We first focus on the level of income $\tilde{W}_{t}$, which is the state variable, and then on the level of capital $\tilde{K}_{t}$ and bonds $\tilde{B}_{t}$. We assume 
that the country starts with an income level, $\tilde{W}_{0}$, below its steady state $\bar{W}$. We show that when $g=g^{*}$, entrepreneurs are constrained on their convergence path and have a demand for liquidity. But they accumulate sufficient funds over time to become unconstrained in the long run. On the other hand, when $g>g^{*}$ entrepreneurs are always constrained in the long run. ${ }^{16}$ We first characterize the balanced growth path with the following proposition:

Proposition 1. An equilibrium where $\tilde{K}_{t}, \tilde{B}_{t}$, and $\tilde{W}_{t}$ are stationary exists. Entrepreneurs are constrained in the stationary equilibrium if $g>g^{*}$ and unconstrained if $g=g^{*}$. This equilibrium is characterized by the following:

(i). $\quad \tilde{K}_{t}=\overline{\tilde{K}}=\left(\alpha\left(\frac{\beta}{1+g}\right)^{2}\right)^{\frac{1}{1-\alpha}}$.

(ii). $\quad \tilde{B}_{t}=\overline{\tilde{B}}=\frac{1-\alpha \beta}{\alpha \beta} \overline{\tilde{K}}$ if $g>g^{*}$ and $\overline{\tilde{B}}$ is undetermined if $g=g^{*}$.

(iii). $\quad \tilde{W}_{t}=\overline{\tilde{W}}=\overline{\tilde{K}}^{\alpha}$ if $g>g^{*}$ and $\overline{\tilde{W}}$ is undetermined if $g=g^{*}$.

- The equilibrium for $\overline{\tilde{B}}$ and $\overline{\tilde{W}}$ is then unique if $g>g^{*}$.

We leave the proof of this proposition to Appendix B. We will instead focus on the dynamics and illustrate this proposition graphically. Let us simply

16. The case $g>g^{*}$ is inconsistent with the small economy assumption in the steady state as the fast-growing country outgrows the rest of the world. However, it is still of interest to examine this case as we will later look at an example where the economy grows temporarily faster. An alternative would be to consider the case $\beta<\beta^{*}$, which also implies that entrepreneurs are constrained in the steady state. While this assumption is commonly used in the literature, we do not find it convincing to explain international capital flows by differences in preferences. 
mention here that the indeterminacy of $\overline{\tilde{B}}$ and $\bar{W}$ when $g=g^{*}$ is a typical feature of unconstrained infinite-horizon small open economies.

The dynamics depend on whether the credit constraint is binding or not. Denote by $\widehat{W}$ the threshold level of revenue above which entrepreneurs are no longer constrained (the value for $\widehat{W}$ is derived in Appendix $\mathrm{B}$ ). Using the definition of $\tilde{W}_{t}$, the dynamics of firms' revenues are described by:

$$
\tilde{W}_{t+2}=\left(\frac{\tilde{K}_{t+1}^{\alpha}}{1+g}\right)+r^{*} \tilde{B}_{t+2}^{2}
$$

where:

$$
\begin{aligned}
& \tilde{K}_{t+1}=\min \left\{\frac{\alpha \beta^{2}}{1+g} \tilde{W}_{t}, \widehat{K}\right\} \\
& \tilde{B}_{t+2}^{2}=\max \left\{0, r^{*} \frac{\beta^{2}}{(1+g)^{2}} \tilde{W}_{t}-\frac{r^{*} \widehat{K}}{1+g}-\frac{\widehat{w}}{(1+g)}\right\}
\end{aligned}
$$

where $\widehat{K}=\left(\alpha / r^{* 2}\right)^{\frac{1}{1-\alpha}}$ is the first-best efficient capital stock. This implies the following dynamics in each of the two cases:

$$
\begin{aligned}
\tilde{W}_{t+2} & =\left[\alpha \frac{\beta^{2}}{(1+g)^{2}} \tilde{W}_{t}\right]^{\alpha} & & \text { if } \tilde{W}_{t}<\widehat{W} \\
& =\frac{r^{* 2} \beta^{2}}{(1+g)^{2}} \tilde{W}_{t} & & \text { if } \tilde{W}_{t} \geq \widehat{W}
\end{aligned}
$$


When $\tilde{W}_{t}<\widehat{W}$, entrepreneurs cannot reach the first-best level of capital, so that $\tilde{K}_{t+1}=\alpha \beta^{2} \tilde{W}_{t} /(1+g)$ and $\tilde{B}_{t+2}^{2}=0$. When $\tilde{W}_{t} \geq \widehat{W}$, firms are sufficiently rich to achieve the first-best level of capital $\tilde{K}_{t+1}=\widehat{K}$. Besides, $\tilde{B}_{t+2}^{2}$ is equal to $r^{*} \beta^{2} \tilde{W}_{t} /(1+g)^{2}-\left(r^{*} \widehat{K}+\widehat{w}\right) /(1+g)$, which represents the amounts of savings cumulated over two periods $\beta^{2} r^{*} \tilde{W}_{t} /(1+g)^{2}$, minus the intertemporal, growth-adjusted, costs of production $\left(r^{*} \widehat{K}+\widehat{w}\right) /(1+g)$. The dynamics of $\tilde{W}$ depend linearly on its past values because (i) under log utility, savings are proportional to revenues, (ii) under constant returns to scale, the return on capital is linear and, (iii) under profit maximization, the returns on capital and bonds are equalized.

Figure 3 represents the dynamics of $\tilde{W}$ when $g=g^{*}$. When $\tilde{W}_{t}<\widehat{W}$, the dynamics are concave because the marginal returns to capital are decreasing, due to a constant labor supply. Since $\tilde{w}_{t}<\widehat{w}$, entrepreneurs' revenues are increasing along these dynamics. This is reflected in the fact that the first part of the curve is above the 45-degree line. The economy reaches its balanced growth path when $\tilde{W}_{t}$ reaches $\widehat{W}$.

To better understand the dynamics, we now turn to the evolution of capital and bonds in the convergence process. The dynamics of $\tilde{K}_{t+1}$ are summarized by (21). $\tilde{B}_{t+1}^{1}$ is then simply the share of saving $\beta \tilde{W}_{t} /(1+g)$ that is not invested in production, while $\tilde{B}_{t+2}^{2}$ is given by (22). Figure 4 shows the evolution of these three variables as a function of $\tilde{W}_{t}$. The first striking result is that $\tilde{K}_{t+1}$ and 
$\tilde{B}_{t+1}^{1}$ both increase in $\tilde{W}_{t}$ when the entrepreneur is constrained $\left(\tilde{W}_{t}<\widehat{W}\right)$. This illustrates the complementarity between the two variables. This contrasts with the unconstrained case $\tilde{W}_{t} \geq \widehat{W}$, where $\tilde{B}_{t+1}^{1}$ increases while $\tilde{K}_{t+1}$ stays constant. The evolution of $\tilde{B}_{t+2}^{2}$ complements the analysis: $\tilde{B}_{t+2}^{2}=0$ when firms are constrained because they liquidate their bond holdings in $t+1$, while $\tilde{B}_{t+2}^{2}$ increases in $\tilde{W}_{t}$ in the unconstrained case. This implies that the domestic net foreign asset will comove with capital when all entrepreneurs are constrained, not when they are unconstrained.

The second result from Figure 4 is that the long-run capital stock corresponds to its first-best level $\widehat{K}$. The reason is that the balanced growth path entails that the propensity to save $\beta$, multiplied by the aggregate return on past saving, accommodates the growth in investment needs $1+g$. This implies that the aggregate return on saving is equal to $(1+g) / \beta$ on the balanced growth path. When $g=g^{*}$, this coincides with the world's interest rate $r^{*}$. The effect of credit constraints is then suppressed in the long run, because the opportunities of arbitrage between bonds and capital vanish. Therefore, despite being constrained during the convergence process, entrepreneurs are not constrained in the balanced growth path.

Figure 5 describes the case $g>g^{*}$. We can see that entrepreneurs are constrained in the neighborhood of $\overline{\tilde{K}}: \bar{W}<\widehat{W}$, i.e., the constraint is binding in the steady state. This is because, when $g>g^{*}$, the long-term return on domestic capital $(1+g) / \beta$ is higher than the world interest rate $r^{*}$. This arbitrage 
opportunity remains because of the presence of binding credit constraints. More precisely, when $g$, which commands the entrepreneurs' investment needs, is large, entrepreneurs become constrained and the return on their saving increases relative to the world's interest rate because they are not able to keep up with the continuing increase in TFP, unless the return on bonds $r^{*}$ or their propensity to save $\beta$ increase.

This last result is important. It means that a higher growth rate overturns the classical result that entrepreneurs are eventually unconstrained. To generate persistent credit constraints, it is therefore not necessary to assume a lower discount factor $\beta$. A higher growth rate plays the same role, since it increases the impatience rate of the economy $(1+g) / \beta$. A demand for liquidity will therefore naturally appear in countries with high growth rates.

When entrepreneurs are constrained in the steady state, there is a simple expression for the current account and the ratio of current account to GDP is constant. Define the current account as $C A_{t}=B_{t+1}-B_{t}$. In a constrained steady state, we find:

$$
\frac{C A_{t}}{Y_{t}}=\frac{(1-\alpha \beta) \beta g}{(1+g)^{2}}
$$

Clearly, the current account surplus is permanently positive and increases with $g$ (as long as $g<1$ ). A similar result can be found for the ratio of investment to GDP. 
To summarize, we find that the economy can be constrained on its convergence path or in a steady state when $g>g^{*}$. In each case, there is a demand for liquidity that has significant macroeconomic implications. It implies a current account surplus generated by high corporate saving. It also coincides with high investment levels and high output growth. All these features, documented in the Introduction, are present in the context of global imbalances.

\subsection{Experiences of Growth}

Experiences of growth in emerging countries can be very different in terms of capital flows, depending on the source of growth. Here we examine two cases that lead to radically different outcomes: an economy experiencing temporarily higher TFP growth and an economy experiencing an improvement of its financial development. First, we examine a TFP growth acceleration episode in the becnchmark case where $\varphi=0$. In this case, there is a need for liquidity that leads to a capital outflow. Second, we consider an increase in $\varphi$ from $\varphi=0$ to $\varphi$ large enough so the entrepreneurs are no longer constrained. This reduces the need for liquidity, which leads to a capital inflow. ${ }^{17}$

17. In order to have a complete assessment of the dynamics of the economy, we need to combine the TFP-adjusted variables with the evolution of TFP, and to aggregate the two groups of entrepreneurs. We do this by assuming that these two groups are of equal size in terms of wealth. In the constrained steady state, this is not an assumption but a result 
3.4.1. A temporary increase in $g$. We first consider the impact of an increase in $g$ starting from a steady state level where $g=g^{*}$. The dynamic equations (21)-(24) hold, but with a different growth rate $g$. In terms of Figure 5, this implies that the economy is temporarily driven by the schedule characterized by $g>g^{*}$. If we start from an initial steady state when $g=g^{*}$, this means that we move from an unconstrained economy, starting at revenues level $\tilde{W}_{0}$, to a constrained one where the liquidity motive becomes effective. In the figure, this is represented by the convergence from $\tilde{W}_{0}$ towards $\bar{W}$. When the economy goes back to its initial growth rate, the economy returns to $\tilde{W}_{0}$. Importantly, during the whole experience, the economy remains on a constrained schedule where capital is proportional to bond holdings and Equation (15) holds.

In fact, during this period, capital, production and wages increase, whether entrepreneurs are constrained or not as a result of TFP growth. The main difference between the constrained and unconstrained economies lies in the reaction of capital flows: capital flows out if entrepreneurs are constrained while it flows in if they are unconstrained. In the constrained case, they have to secure liquidity ex ante, during the investment phase, in order to pay for the wage bill. More precisely, the net foreign asset position stays proportional to output $(B / Y$ is constant) since bonds and capital are proportional, as

\footnotetext{
stemming from the equal number of entrepreneurs in each group and the unique steady state. However, when we consider the convergence dynamics, we have to make assumptions on the initial wealth of the two groups.
} 
implied by Equation (15). As output grows, net foreign assets grow as well and the current account increases, as suggested by Equation (25). In the unconstrained case, entrepreneurs can rely on a free access to financial markets to borrow in the production phase and the current account becomes negative. This temporary growth period leading to capital outflows from a constrained economy is consistent with recent global imbalances since the emerging economy experiences capital outflows. ${ }^{18}$

3.4.2. A permanent increase in $\varphi$. We now consider an episode of financial liberalization, where a country suddenly increases its level of financial development measured by $\varphi$. Consider the extreme case of a country that switches instantaneously from a fully constrained state $(\varphi=0)$ to an unconstrained one ( $\varphi$ large), while it is converging to the steady state with $g=g^{*}$. The effect of such an experiment is straightforward and is represented in Figure 4 . Assume that $\varphi$ increases when revenues are at $\tilde{W}_{0}$. The stock of capital jumps permanently from the constrained level to its higher unconstrained level $\widehat{K}$, which generates temporary growth. Bonds on the other hand, jump permanently to a lower level, which generates capital inflows.

18. Due to the benchmark model's simplicity, the net foreign asset position remains a constant fraction of output (since it is a constant fraction of capital). We will show that this is not the case in the calibrated version of the model. 
This experiment shows that reforms promoting financial development generate a phase of output growth with capital inflows (this outcome is typical in models with credit constraints). In this case, the demand for liquidity is not the dominant mechanism. On the contrary, domestic reforms improving the functioning of financial markets reduce or eliminate the need for liquidity, which enables a higher investment. Consequently, there is no systematic link between capital flows and growth and the relationship depends on the source of growth.

\subsection{Calibrated Dynamics and Sensitivity Analysis}

So far, we have used the benchmark model for its tractability. However, this benchmark model is based on extreme assumptions: $\varphi=0, \kappa=1$ and $\delta=1$. Here, we relax these assumptions and calibrate the parameters more accurately. We analyze numerically the dynamic response to growth shocks. We then explore the sensitivity of our results to various parameters.

3.5.1. Baseline calibration. Following the literature, the capital depreciation rate is set to $10 \%$, the share of capital $\alpha$ is set to 0.3 and $\beta=1 / r^{*}=0.95$. The calibration of $\varphi$ is based on Song et al. (2011). During the period 19972003, the share of investment financed by bank loans and government budgets 
in domestic private enterprises ranged between $5 \%$ and $12 \% .{ }^{19}$ We therefore set $\varphi=0.1 .{ }^{20}$ Contrary to $\varphi$, there is no direct measure of $\kappa$. We therefore use an indirect measure, which is the cash ratio. In our model, it corresponds to $B^{1} / K$. Huang and Zhang (2011) provide the cash ratio for a broad sample of countries, including Emerging Asia. ${ }^{21}$ The weighted average of the cash ratio in Emerging Asia is 0.16 , which yields $\kappa=0.42$. We normalize TFP $A$ to 1 in the first period.

The average growth rate is matched to the data, assuming smooth growth dynamics. We assume $g_{t+1}=\mu g_{t}$, with $\mu=0.9$. These growth dynamics are designed to describe a catching-up episode in the Emerging country, where growth is initially high and then slowly decays. We then have to set $g_{0}$ so that the growth of the Emerging country corresponds to the growth of Emerging Asia between 1990 and 2008. We normalize $g^{*}$ to zero, so that $g$ is the growth

19. Figure 4 in their paper shows the share of investment financed by bank loans and government budgets for state-owned enterprises (SOE), domestic private enterprises (DPE) and foreign enterprises (FE) in China. DPE are the ones that correspond the most to the credit-constrained enterprises of our model. Besides, they show that DPE accounted accounted for the bulk of Chinese growth in the 2000s.

20. This number is also consistent with Jain-Chandra et al. (2009, p. 63), who document that domestic lending represented less than $10 \%$ of fixed-asset investment in China in the 1995-2008 period.

21. In Emerging Asia we include the following countries: China, Hong Kong, India, Indonesia, South Korea, Malaysia, Philippines, Taiwan and Thailand. 
of Emerging Asia relative to the rest of the world, which in our approach is represented by the G7. In 1990, Emerging Asia's GDP represented $22 \%$ of the G7's GDP. In 2008, it represented 55\% of the G7's GDP. This amounts to an average relative growth rate of $2.3 \%$. We match this average growth rate by setting $g_{0}=10 \%$.

Consider now the impact of such a growth episode in a constrained economy within the calibrated model. In Figure 6, we compare the effect of this growth acceleration on an economy with imperfect financial markets ("Constrained", represented by the solid lines), whose dynamics are described by (30) and (31), to an economy with perfect financial markets ("Unconstrained", represented by the dashed lines), i.e., with $\varphi$ large enough so that entrepreneurs are never constrained. In order to make the two cases comparable, we set the initial steady state of bonds in the unconstrained model equal to that of the constrained one. We consider capital, production and wages, represented as percentages of the initial steady state; and bonds and the current account, represented as a percentage of GDP. These bonds are also decomposed into the bond demand by entrepreneurs who are at the investment stage of their project, $B^{1}$, and the bond demand by entrepreneurs who are at the production stage, $B^{2}$.

During 25 periods, domestic TFP increases steadily until it reaches a level 2.5 times higher than initially. Consider now the impact of such a growth episode in a constrained economy, represented by the solid lines in Figure 6 ("Constrained"), along with the impact on an unconstrained economy 
("Unconstrained"). ${ }^{22}$ During this period, capital, production and wages increase, whether entrepreneurs are constrained or not. When entrepreneurs face financial frictions, however, capital accumulation is delayed. In that case, entrepreneurs can invest only after their revenues have sufficiently increased. Regarding capital flows, we observe a stark contrast between the constrained case, where the economy experiences capital outflows, with the unconstrained case, where the economy experiences substantial capital inflows.

Notice that capital even decreases slightly in the beginning of the growth episode. This is due to partial capital depreciation which implies that the productivity of workers rises relatively more than that of capital, because TFP does not affect the remaining capital stock. Entrepreneurs therefore use their limited resources primarily to hire workers. This also explains the fact that net foreign assets increase not only in levels but also as a share of GDP, contrary to the benchmark model. Indeed, the relatively high labor demand results in a relatively high wage, which the entrepreneurs finance by holding more liquidity. Besides, the initial decrease in capital stock reduces collateral and hence the financing capacities of borrowing firms.

Finally, the current account increases, which is consistent with Figure 2, as it implies that corporate saving increases more than investment. It actually rises on impact to a level equivalent to $2 \%$ of GDP. This figure is of the same order

22. The simulations are run using Dynare (Juillard, 1996). 
of magnitude as what is observed in the data. The evolution of the current account is less persistent than in the data though, which gives an average figure of $1 \%$ over 10 years, mainly because the growth acceleration is transitory in our simulation. Notice, however, that this number is an assessment of the contribution of corporate savings to current account surpluses and abstracts from the role of other factors.

3.5.2. Sensitivity. Here we examine the sensitivity of the results to different values of $\varphi$ and $\kappa . \varphi$ is set to 0.05 and 0.25 , along with its baseline calibration value $0.1 . \kappa$ is set to 0.2 and 0.6 , along with its baseline value 0.42 . The results are represented in Figure 7. Since the effects on capital, production and wages are very similar across the different calibrations, we do not represent them.

The higher $\varphi$, the lower the net foreign asset position $B$ in the steady state. For the high value of 0.25 , it even turns negative. During the growth episode, in the case with $\varphi=0.25$, the economy experiences cumulated capital inflows rather than outflows, but may experience short-lived capital outflows as the collateral initially decreases. With a low $\varphi$, the economy experiences capital outflows all along the growth episode as in the baseline calibration. While on impact the current account increases slightly less than in the baseline, capital outflows are larger in cumulated terms. Similarly, a lower $\kappa$ implies a smaller net foreign asset position $B$. Indeed, for a given borrowing $B^{2}$, firms need to hold less liquidity $B^{1}$ to pay for a smaller share of the wage bill. For the low value of 0.2 , the net foreign asset position turns negative. The economy still 
experiences capital outflows for all the values of $\kappa$ considered. Besides, the larger $\kappa$, the larger the capital outflows. Overall, the proportional increase in the demand for liquidity in presence of higher growth is robust to changes in these two parameters.

\section{Global imbalances}

The analysis so far has been conducted by assuming that the emerging country is small, so that the interest rate is given. When we extend our analysis to a two-country economy, we find that the demand for liquidity in an emerging country leads to a lower world interest rate, higher investment and output in the rest of the world, and larger global imbalances. We show that these imbalances remain as long as the demand for liquidity is effective, in particular as long as the emerging economy has a higher TFP growth. We consider an asymmetric world composed of an Emerging country similar to the one studied earlier and an Industrial country with a high level of financial development, so that entrepreneurs are never constrained. Industrial country variables are denoted with an asterisk, so that $\varphi^{*}$ is large. The two countries are linked through the bond market as they can trade one-period bonds. Productivities $A_{t}$ and $A_{t}^{*}$ grow respectively at rate $g$ and $g^{*}$. Otherwise, the two countries have the same characteristics.

We first study a balanced growth path within the benchmark model where the Emerging country grows at a permanently higher growth rate than the 
Industrial country. Though unrealistic, the dynamics of the growth path are informative. We can show that a permanently higher growth rate in the Emerging country generates a permanent liquidity demand and a permanent current account surplus. Second, we consider the case where both countries grow at the same rate in the long run but with $g$ temporarily larger than $g^{*}$. This experiment is simulated using the baseline calibration described in Section 3.5 .

\subsection{Balanced Growth Path}

The balanced growth path with $g$ permanently higher than $g^{*}$ is characterized in Appendix B. Let $\tilde{K}_{t}^{*}=K_{t}^{*} / A_{t}$ be the Industrial capital stock normalized by Emerging TFP. Let also $\widetilde{r}_{t}$ be the normalized interest rate: $\widetilde{r}_{t}=r_{t}\left(A_{t} / A_{t}^{*}\right)^{\frac{1-\alpha}{2}}$. The following Proposition characterizes a steady state where the Emerging country entrepreneurs are constrained.

Proposition 2. Assume $g>g^{*}$. When $t$ goes to infinity, a growth path where entrepreneurs are constrained and $\tilde{K}_{t}, \tilde{K}_{t}^{*}, \tilde{B}_{t}$, and $\widetilde{r}_{t}$ are stationary exists and is characterized by the following:

(i). $\quad \tilde{K}_{t}=\overline{\tilde{K}}=\left(\frac{\alpha \beta^{2}}{(1+g)^{2}}\right)^{\frac{1}{1-\alpha}}$
(ii). $\tilde{K}_{t}^{*}=\overline{\tilde{K}}^{*}=\frac{1-\alpha \beta}{\alpha \beta} \overline{\tilde{K}}$
(iii). $\tilde{B}_{t}=\overline{\tilde{B}}=\frac{1-\alpha \beta}{\alpha \beta} \overline{\tilde{K}}$
(iv). $\tilde{r}_{t}=\overline{\widetilde{r}}=\left[\alpha\left(\overline{\tilde{K}}^{*}\right)^{\alpha-1}\left(\frac{1+g}{1+g^{*}}\right)^{\frac{1-\alpha}{2}}\right]^{\frac{1}{2}}$ 
The steady-state Emerging capital stock and bonds are the same as in the small open economy (see Proposition 1). Since $g>g^{*}$, the Emerging country is always constrained so that the liquidity demand implies that capital and bonds move in parallel. The interesting new result in the two-country economy is that the Industrial capital stock grows at the Emerging country growth rate. Moreover, Proposition 2 implies that the "imbalance" of the Industrial country, measured as $B_{t}^{*} / Y_{t}^{*}$, grows more negative over time. In other words, if the Emerging country grows permanently faster than the Industrial country, global imbalances can grow permanently.

Both countries benefit from global imbalances in the balanced growth path. Since Industrial entrepreneurs are unconstrained, they are the providers of liquidity to Emerging entrepreneurs. This enables a higher growth in the Emerging country. At the same time, Industrial entrepreneurs receive cheaper funding from Emerging entrepreneurs, which allows them to increase their capital stock at the same rate as Emerging productivity. Indeed, the liquidity need for the Emerging economy grows, whereas the capacity of the Industrial economy to provide liquidity does not grow as fast. As a result, the world interest rate goes to zero, reflecting the increasing price of liquidity. This increasing price of liquidity constitutes a rent for the Industrial country which 
enables its output to grow at a higher rate than its fundamental growth rate $g^{*} \cdot 23$

\subsection{A Temporary Increase in $g$}

A more realistic scenario is to assume that the higher growth rate in the Emerging country is temporary. Here, we simulate the impact of the same temporary increase in the domestic growth rate as in Section 5.3. We also use the same calibrated parameters for the Emerging country. The parameters for the Industrial country are the same as the Emerging country, except that $\varphi^{*}$ is high enough so that firms are unconstrained, and $\kappa^{*}$ is set to 0.6 . This value is chosen to obtain a steady-state "cash ratio" of 0.15 , which is the weighted average of the cash ratio in the G7 countries, as reproduced in Huang and Zhang (2011). ${ }^{24}$ Besides, whereas the initial Emerging country's TFP $A_{0}$ is normalized to 1 , we set the Industrial country's TFP $A_{t}^{*}$ to 4 , so that the initial Emerging country's GDP represents $25 \%$ of the Industrial one, which corresponds to the size of Emerging Asia relative to the G7 in 1990.

23. It can be shown that consumption in the Industrial country also grows at a rate higher than $g^{*}$. However consumption and output do not grow as fast as in the Emerging country, so the relative size of the Industrial country becomes infinitely small.

24. This value is also consistent with the calibration of Bacchetta et al. (2014) based on U.S. data. 
We compare the resulting effects when the Emerging country is constrained and when it is unconstrained. Figure 8 shows the dynamics of capital, output, and net foreign asset positions in both countries. It also shows the evolution of the world interest rate. More specifically, it shows the two-period interest rate relevant to entrepeneurs, $R_{t}=r_{t+1} r_{t+2}$. Finally, Figure 8 shows the evolution of relative wages. The reaction of the Emerging economy resembles the reaction of the small open economy studied in the previous section. This implies that the Emerging country experiences capital outflows instead of capital inflows, which translates into global imbalances: the debt level of the Industrial country has to increase.

The impact on the world interest rate differs dramatically in the constrained and unconstrained cases. In order to make the Industrial country more willing to supply bonds, the world interest rate has to decrease in the constrained case. In the unconstrained case, on the contrary, the interest rate increases as a response to the decrease in bond demand. As a result, the Industrial capital stock increases in the constrained case, while the opposite happens in the unconstrained case.

\section{Discussion}

The model has been kept simple to illustrate the mechanism behind the demand for liquidity. But this mechanism holds in a wider context. In this section we examine three important extensions: i) FDI; ii) capital account liberalization; 
iii) public debt and international reserves. While the basic mechanism may still hold in each of these extensions, they each add interesting elements to the analysis.

\subsection{Foreign Direct Investment}

In the benchmark case (when $\varphi=0$ ), the demand for liquidity equals net capital flows. In reality, however, the demand for liquid assets coexists with other types of flows, because of the limited domestic supply of liquidity. A special type of flow is FDI. We can show that our model can generate FDI inflows along with outflows of bonds if the level of development in the Emerging country is not too high (see the Technical Appendix for a detailed discussion).

A simple way of introducing FDI in our model is to assume that it is undertaken by unconstrained investors from the Industrial country. ${ }^{25}$ However, given the simplicity of our model this assumption may imply that unconstrained Industrial investors partially or fully crowd out Emerging entrepreneurs. To avoid this, we make three further assumptions. First, there is an increasing cost for Industrial entrepreneurs to invest in the Emerging country. This cost rules out indeterminacy for the quantity of FDI in equilibrium. Second, workers have a reservation wage $\underline{w}$ so that labor supply is infinitely elastic at $\underline{w}$ and is equal to 1 whenever $\tilde{w}>\underline{w}$. Third, we assume that the level of development

25. See Kiribaeva and Razin (2010) for a survey on different ways to model FDI. 
is low, so that the Emerging country is in a situation of unemployment where workers are paid their reservation wage $\underline{w}$. This happens when the wage level $\tilde{w}$ that would bring full employment $(l=1)$ is below the reservation wage. In that case, FDI increases total labor demand, but it has no impact on the wage rate and therefore no spillover effect on existing Emerging entrepreneurs.

More specifically, we can assume a cost $\tau$ of the iceberg type that increases with the aggregate amount of labor used, so it is not internalized by the foreign firms. Let $l^{F}$ be the amount of labor used by FDI and assume that $\tau=\tau\left(l^{F}\right)$ with $\tau(0)=0$ and $\tau^{\prime}>0 .{ }^{26}$ This implies the following labor demand by foreign firms (see the Technical Appendix for details):

$$
l^{F}\left(\tilde{w}_{t+1}\right)=\tau^{-1}\left[1-\left(\frac{\tilde{w}_{t+1}}{\widehat{w}}\right)^{1-\alpha}\right]
$$

Similarly, we can write the labor demand by domestic firms as:

$$
l\left(\tilde{w}_{t+1}, \tilde{K}_{t+1}\right)=\frac{(1-\alpha) r^{*}}{\alpha \tilde{w}_{t+1}} \tilde{K}_{t+1}
$$

where $\tilde{K}_{t+1}$ is independently defined by past capital and labor.

Now assume that the Emerging country opens to FDI when wages are at $\underline{w}$ and that FDI is not too large so that wages do not increase. In other terms

26. This implies that the profit function for FDI is $\pi\left(K_{t+1}^{F}, l_{t+1}^{F}\right)=(1-$ $\tau) A_{t+1} K_{t+1}^{F \alpha} l_{t+1}^{F 1-\alpha}-r_{t+1} r_{t+2} K_{t+1}^{F}-r_{t+2} w_{t+1} l_{t+1}^{F}$ 
total demand at $\underline{w}$ is less than one:

$$
l^{F}(\underline{w})+l\left(\underline{w}, \tilde{K}_{t+1}\right)<1
$$

In this case, Emerging entrepreneurs are not affected by FDI and keep their liquidity demand, so that both types of capital flows can coexist. As $\tilde{K}_{t}$ grows, however, labor demand grows and (28) will no longer hold. The wage rate has to adjust so that:

$$
l^{F}\left(\tilde{w}_{t+1}\right)+l\left(\tilde{w}_{t+1}, \tilde{K}_{t+1}\right)=1
$$

In this case, the dynamics of capital flows become more complex and depend on the details of the model. ${ }^{27}$

\subsection{Capital Account Liberalization}

A demand for liquidity also changes the implications of a capital account liberalization. There is an extensive literature analyzing the implications of liberalizing international capital flows. When an economy has a low level of financial development, such a liberalization typically implies a capital inflow

27. However, we can expect that, as the Emerging country becomes richer, entrepreneurs are able to hire more workers, which increases the demand for labor and inflates the wage. This would crowd out FDI. The Emerging country should experience a relative increase in domestic holdings of liquid assets and a relative decrease in foreign holdings of FDI. However, as the economy experiences TFP growth, it may still experience FDI inflows. 
and an increase in investment, at least in the short run. ${ }^{28}$ In contrast, with a demand for liquidity, while there is an increase in investment there is always an initial capital outflow.

To study a capital account liberalization, we simply need to analyze the Emerging economy in autarky and then examine the convergence to its open economy steady state. Since the economy is scarce in liquid assets, the domestic return on bonds is lower than the world's interest rate. On impact, the capital stock slowly increases and is accompanied by a capital outflow. This is made possible by the increase in the return on bonds. Then entrepreneurs gradually accumulate profits. They can then invest more and increase their demand for liquidity. In a two-country model, the capital account liberalization implies an increasing current account deficit in the Industrial economy.

\subsection{Domestic Liquidity and Public Flows}

Introducing a public sector could definitely add additional motives for capital flows (e.g., Aguiar and Amador, 2011). However, the basic mechanism presented in this paper is not necessarily affected by the presence of a public sector or by a significant role of public flows. First, the presence of public debt does not affect the supply of liquidity in an open economy. In the context of a

28. E.g. see Aghion et al. (2004), Aoki et al. (2009), Bacchetta (1992), or Martin and Taddei (2013). In Angeletos and Panousi (2011), a capital account liberalization implies an initial capital outflow, but is accompanied by a decline in investment. 
closed economy, it is well known that the government may alleviate the liquidity constraint by issuing liquid public debt (e.g., see Woodford, 1990). But this is no longer the case in an open economy with well integrated financial markets. In this context, entrepreneurs have ample access to liquid assets in foreign countries and changes in the supply of domestic assets have little or no impact. Nevertheless, there are two potential channels through which an increase in public debt might have an impact. First, it can affect the world interest rate. This channel obviously disappears in a small open economy. Second, the increase in debt may be associated with a reduction in taxes that have real effects. Since Ricardian equivalence does not hold due to financial constraints, a decrease in taxes on entrepreneurs increases investment.However, this channel is related to tax policy rather than changes in liquidity supply.

With limited financial integration, the supply of public debt may have a significant impact on investment. However, the impact of liquidity demand on net foreign assets depends on the government's behavior. The public sector may simply play the role of intermediary between the domestic financial sector and foreign borrowers. This situation actually corresponds to the recent Chinese experience (see Song et al., 2011). With strong capital controls in place, the central bank has been buying substantial amounts of international reserves, while at the same time it has been issuing domestic debt. ${ }^{29}$ In other terms,

29. Bacchetta et al. (2013) analyze the optimal reserve policy by a central bank, when the private sector of a small economy does not have access to international capital markets. 
the demand for liquidity by the private sector is not necessarily translated into private capital flows and may be consistent with the significant role of public flows (see Alfaro et al., 2014).

\section{Conclusion}

In this paper, we propose a simple mechanism generating a demand for liquid assets in a dynamic small open macroeconomic model. This demand emanates from firms and is proportional to their saving. Such a demand can generate a current account surplus in fast-growing emerging economies, where firms face tighter credit constraints. In such a context, the demand for foreign bonds becomes a complement to investment. This implies that an increase in growth and in investment is accompanied by a net capital outflow, which is the opposite of the standard intertemporal model's predictions. We show that the demand for liquidity can arise on the convergence path of an economy with an initial low level of capital. It can also occur close to a steady state, if the economy grows faster than the rest of the world.

When we cast this mechanism in a two-country model, it gives a framework consistent with global imbalances and with all the symptoms observed in a

They find that the optimal policy is close to the behavior of an economy with full capital mobility. The central bank issues public debt to match a demand for liquidity and uses the funds to buy foreign assets. 
"saving glut". Both countries benefit from these imbalances. On the one hand, the Emerging country can grow faster thanks to the liquidity provided by the unconstrained Industrial country. On the other hand, the Industrial country can build a higher capital stock thanks to the funds provided by the Emerging country. In addition to a sustained current account surplus in the Emerging economy, the model is consistent with a number of stylized facts observed in recent years. In particular, current account surpluses have been accompanied by a large level of corporate saving, a large level of investment, and rapid growth in emerging Asia. The existing literature cannot explain these facts jointly. Moreover, the model is consistent with the empirical evidence on the allocation puzzle and with the positive correlation between saving and growth. We also argue that the framework can be consistent with an increase in reserves, as is observed in China and other countries, when there are capital controls and the central bank plays the role of intermediary between the private sector and the international asset market. Moreover, we showed that the demand for liquid assets can also coincide with FDI inflows. Finally, we notice that the model predicts a decline in global imbalances when growth declines, either in the Emerging or in the Industrial country (see Bacchetta and Benhima, 2014).

\section{Appendix A: Data Description}

\section{List of countries}


- Emerging Asia: China, India, Philippines, Republic of Korea, Taiwan, Thailand.

- Other emerging: Czech Republic, Kazakhstan, Kyrgyzstan, Mexico, Poland, Republic of Moldova, Tunisia, Ukraine.

- Developed include G7 countries and Australia, Belgium, Denmark, Finland, Netherlands, Norway, Sweden, Switzerland.

\section{Data source}

- Gross corporate saving and gross fixed capital formation:

- United Nations data (Table 4.8 Combined Sectors: Non-Financial and Financial Corporations (S.11 + S.12) - ITEM: Gross Saving and Table 4.1 Total Economy (S.1) - ITEM: Gross Fixed Capital Formation).

- For India, Thailand, and Taiwan: CEIC (based on national sources).

- For China, Kazakhstan, Kyrgyzstan, Republic of Moldova, Tunisia, Ukraine: Gross corporate saving is the sum of gross saving of non-financial and financial corporations (Tables 4.3 Non-financial Corporations (S.11) and 4.4 Financial Corporations (S.12) - ITEM: Gross Saving).

- For Philippines: Gross corporate saving is total gross saving minus gross saving of the general government and households (Tables 4.1 Total Economy (S.1), 4.5 General Government (S.13), and 4.6 Households (S.14)- ITEM: Gross Saving).

- Nominal and Real GDP: World Bank data. 


\section{Appendix B: Proofs}

\section{Small open economy}

First it is convenient to define three auxiliary variables. Define $\widehat{\beta}=[\beta /(1+g)]^{2}$, $\widehat{g}=\left[(1+g) /\left(1+g^{*}\right)\right]^{2}$, and $\underline{\widehat{w}}=\underline{w} /(1-\alpha) r^{*}$. In order to prove the existence and unicity of the steady state, we establish the following lemma:

LEMMA 1. The entrepreneurs' revenues $\tilde{W}$ in the emerging country evolve according to:

$$
\begin{aligned}
\tilde{W}_{t+2} & =\left[\alpha \widehat{\beta} \tilde{W}_{t}\right]^{\alpha} & \text { if } \tilde{W}_{t}<\widehat{W} \\
& =\frac{\tilde{W}_{t}}{\widehat{g}} & \text { if } \tilde{W}_{t} \geq \widehat{W}
\end{aligned}
$$

with $\widehat{W}=\widehat{K}^{\alpha} \widehat{g}$

\section{Proof:}

Only two situations can exist: (1) Constrained firms ; (2) Unconstrained firms. The different dynamic equations for $W$ correspond to these different types of equilibria in the labor market.

1. In the equilibrium with constrained firms, $\tilde{K}_{t+1}=\alpha \widehat{\beta} \tilde{W}_{t}$ so the dynamics of revenues follow

$$
\tilde{W}_{t+2}=\left[\alpha \widehat{\beta} \tilde{W}_{t}\right]^{\alpha} l_{t+1}^{1-\alpha}
$$


Since $l_{t}=1$ in equilibrium, this yields $(30)$.

2. When firms are unconstrained, the dynamics of revenues must satisfy:

$$
\tilde{W}_{t+2}=r^{*} \tilde{B}_{t+2}^{2}+\frac{r^{* 2}}{\alpha(1+g)} \widehat{K}
$$

with $\tilde{B}_{t+2}^{2}=r^{*}\left[\widehat{\beta} \tilde{W}_{t}-\widehat{K} / \alpha(1+g)\right]$. Hence (31).

The first-best capital stock $\widehat{K}$ is implementable only if it is lower than the constrained level of capital: $\widehat{K} \leq \alpha \widehat{\beta} \tilde{W}_{t}$., which is equivalent to $\tilde{W}_{t} \geq \widehat{W}$, with $\widehat{W}=\widehat{K}^{\alpha} \widehat{g}$.

\section{Proof of Proposition 1}

We examine the different dynamic equations summarized in Lemma 1 in order to determine the steady state(s):

1. According to Lemma 1, if $\tilde{W}_{t}<\widehat{W}$, then the dynamics of $\tilde{W}$ follow (30). Consequently, $\tilde{W}_{t+2}>\tilde{W}_{t}$ if and only if $\tilde{W}_{t}<(\alpha \widehat{\beta})^{\frac{\alpha}{1-\alpha}}$. Besides, if $g>g^{*}$, then $(\alpha \widehat{\beta})^{\frac{\alpha}{1-\alpha}} \in\left[0, W_{1}\right)$. In that case, there exists a unique fixed point $\overline{\tilde{W}}=(\alpha \widehat{\beta})^{\frac{\alpha}{1-\alpha}}$ to the dynamic equation of wealth in the interval $[0, \widehat{W})$ where entrepreneurs are constrained. If $g=g^{*}$, then $(\alpha \widehat{\beta})^{\frac{\alpha}{1-\alpha}} \notin\left[0, W_{1}\right)$. There is no fixed point in this interval.

2. Similarly, if $\tilde{W}_{t} \geq \widehat{W}$, then any $\tilde{W}_{t}$ is stationary if $g=g^{*}$, since $\tilde{W}_{t+2}=\tilde{W}_{t}$. If $g>g^{*}$, then $\tilde{W}_{t+2}<\tilde{W}_{t}$, and there is no fixed point in this interval.

To sum up, when $g=g^{*}$, any $\tilde{W} \geq \widehat{W}$ is a steady state. This steady state is characterized by $\tilde{K}_{t+1}=\widehat{K}, \tilde{B}_{t+1}^{1}=\beta \tilde{W}_{t} /(1+g)-\widehat{K}$ and $\tilde{B}_{t+2}^{2}=$ 
$r^{*} \beta^{2} \tilde{W}_{t} /(1+g)^{2}-\left(r^{*} \widehat{K}+\widehat{w}\right) /(1+g) . \tilde{B}_{t+1}=\tilde{B}_{t+1}^{1}+\tilde{B}_{t+1}^{2}$ is therefore pinned down by $\tilde{W}_{t}$ and $\tilde{W}_{t-1}$. For $g>g^{*}$, there is a unique steady state $\overline{\tilde{W}}=(\alpha \widehat{\beta})^{\frac{\alpha}{1-\alpha}}$. This steady state is characterized by $\tilde{K}_{t+1}=\alpha \beta^{2} \tilde{\bar{W}} /(1+g), \tilde{B}_{t+1}^{2}=0$ and $\tilde{B}_{t+1}=\tilde{B}_{t+1}^{1}=\beta(1-\alpha \beta) \bar{W} /(1+g)$.

\section{Two-country economy}

We assume that $0 \leq g^{*}<g$, so the Emerging country grows faster than the Industrial country. In this case, when entrepreneurs are constrained, the dynamic equation for the emerging country is the following:

$$
\tilde{K}_{t+1}=\alpha \widehat{\beta} \tilde{K}_{t-1}^{\alpha}
$$

On the other hand, the industrial country's capital must satisfy:

$$
\alpha\left(\frac{A_{t}}{A_{t}^{*}} \tilde{K}_{t}^{*}\right)^{-(1-\alpha)}=r_{t} r_{t+1}
$$

Proof of Proposition 2: We conjecture that such a stationary growth path exists and then we verify that it satisfies (i)-(iv), and that the Emerging country would indeed stay constrained under (i)-(iv).

If the emerging country is constrained, then (34) holds. The stationary solution for $\tilde{K}$ is $(\alpha \widehat{\beta})^{\frac{1}{1-\alpha}}$, hence (i). (iii) derives directly from the relationship of $B_{t}$ and $K_{t}$ when the entrepreneurs are constrained. In order to determine the stationary values of $\widetilde{r}_{t}$ and $\tilde{K}_{t}^{*}$, consider the aggregate dynamics of the 
Industrial country:

$$
B_{t+1}^{1 *}+B_{t+1}^{2 *}+K_{t+1}^{*}=\beta Y_{t-1}^{*}-\frac{Y_{t+1}^{*}}{r_{t+1}}+\beta r_{t}\left(K_{t}^{*}+B_{t}^{1 *}+B_{t}^{2 *}\right)
$$

Equilibrium in the international bond market yields:

$$
K_{t+1}^{*}-B_{t+1}=\beta Y_{t-1}^{*}-\frac{Y_{t+1}^{*}}{r_{t+1}}+\beta r_{t}\left(K_{t}^{*}-B_{t}\right)
$$

Dividing by $A_{t+1}$ and rearranging, we obtain:

$$
\begin{aligned}
\tilde{K}_{t+1}^{*}-\tilde{B}_{t+1}^{*}= & \beta\left(\frac{A_{0}^{*}\left(1+g^{*}\right)^{t-1}}{A_{0}(1+g)^{t-1}}\right)^{1-\alpha}\left(\tilde{K}_{t-1}^{*}\right)^{\alpha}\left(\frac{1}{(1+g)^{2}}\right) \\
& -\left(\frac{A_{0}^{*}\left(1+g^{*}\right)^{t+1}}{A_{0}(1+g)^{t+1}}\right)^{\frac{1-\alpha}{2}}\left(\tilde{K}_{t+1}^{*}\right)^{\alpha}\left(\frac{1}{\tilde{r}_{t+1}}\right) \\
& +\beta \tilde{r}_{t}\left(\frac{A_{0}^{*}\left(1+g^{*}\right)^{t}}{A_{0}(1+g)^{t}}\right)^{\frac{1-\alpha}{2}}\left(\tilde{K}_{t}^{*}-\tilde{B}_{t}^{*}\right)\left(\frac{1}{1+g}\right)
\end{aligned}
$$

$\tilde{K}_{t}^{*}, \tilde{B}_{t}$ and $\tilde{r}_{t}$ stationary imply that the right-hand side goes to zero when $t$ goes to infinity. This yields that $\overline{\tilde{K}}^{*}=\overline{\tilde{B}}$, hence (ii). (iv) derives directly from (35) and (ii).

In order to prove that this defines an equilibrium where the Emerging country is constrained, it is sufficient to show that $\overline{\tilde{K}}$ is lower than the level of capital per efficient unit of labor that would prevail absent credit constraints with the given interest rate. This level is given by $\overline{\tilde{K}}^{*} A_{t} / A_{t}^{*}$, which goes to infinity when $t$ is large. This confirms that the emerging country is constrained.

It can be shown that consumption in the Industrial country grows at rate $\left(1+g^{*}\right)^{1-\alpha}(1+g)^{\alpha}$. It can also be shown that despite a growing debt, 
the Industrial country does satisfy its Non-Ponzi-Game (NPG) condition under some mild hypotheses. In short, the present value of the Industrial country's net wealth $\beta^{t}\left(K_{t+1}^{*}-B_{t+1}\right) / c_{t}^{*}$ grows/decreases at rate $\beta[(1+$ $\left.g) /\left(1+g^{*}\right)\right]^{(1-\alpha) t / 2}$. For the NPG condition to be satisfied, we need that $\beta\left[(1+g) /\left(1+g^{*}\right)\right]^{(1-\alpha) t / 2}<1 .^{30}$

\section{References}

[1] Aghion, Philippe, George-Marios Angeletos, Abhijit Banerjee and Kalina Manova (2010). "Volatility and Growth: Credit Constraints and the Composition of Investment." Journal of Monetary Economics, 57, 246-265.

[2] Aghion, Philippe, Philippe Bacchetta and Abhijit Banerjee (2004). "Financial Development and the Instability of Open Economies." Journal of Monetary Economics, 51, 1077-1106.

[3] Aguiar, Mark and Manuel Amador (2011). "Growth in the Shadow of Expropriation." Quarterly Journal of Economics, 126, 651-697.

[4] Alfaro, Laura, Sebnem Kalemli-Ozcan and Vadym Volosovych (2014). "Sovereigns, Upstream Capital Flows, and Global Imbalances." Journal of European Economic Association.

[5] Almeida, Heitor, Murillo Campello and Michael S. Weisbach (2004). "The Cash Flow Sensitivity of Cash." The Journal of Finance, 59, 1777-1804.

30. The detailed proof is available on request. 
[6] Angeletos, George-Marios and Vasia Panousi (2011). "Financial Integration, Entrepreneurial Risk and Global Dynamics." Journal of Economic Theory, 146, 863-896.

[7] Aoki, Kosuke, Gianluca Benigno and Nobuhiro Kiyotaki (2010). "Adjusting to Capital Account Liberalization." CEPR Discussion Paper No. 8087.

[8] Bacchetta, Philippe (1992). "Liberalization of Capital Movements and of the Domestic Financial System." Economica, 59, 465-474.

[9] Bacchetta, Philippe and Kenza Benhima (2014). "Corporate Saving in Global Rebalancing." Swiss Finance Institute Research Paper No. 13-35.

[10] Bacchetta, Philippe, Kenza Benhima and Yannick Kalantzis (2013). "Capital Controls with International Reserve Accumulation: Can this Be Optimal?" American Economic Journal: Macroeconomics, 5(3), 229-262.

[11] Bacchetta, Philippe, Kenza Benhima and Céline Poilly (2014). "Corporate Cash and Employment." Swiss Finance Institute Research Paper No. 1401.

[12] Barth III, Marvin J. and Valérie A. Ramey (2002). "The Cost Channel of Monetary Transmission." NBER Macroeconomics Annual 2001, 16, 199256.

[13] Bayoumi, Tamim, Hui Tong and Shang-Jin Wei (2013). "The Chinese Corporate Savings Puzzle: A Firm-Level Cross-Country Perspective." In Capitalizing China, edited by Joseph P.H. Fan and Randall Morck. University of Chicago Press, pp. 283-308. 
[14] Benhima, Kenza (2013). "A Reappraisal of the Allocation Puzzle through the Portfolio Approach." Journal of International Economics, 89, 331-346.

[15] Buera, Francisco J. and Yongseok Shin (2010). "Productivity Growth and Capital Flows: The Dynamics of Reforms." Mimeo, UCLA.

[16] Caballero, Ricardo J., Emmanuel Farhi and Pierre-Olivier Gourinchas (2008). "An Equilibrium Model of "Global Imbalances" and Low Interest Rates." American Economic Review, 98(1), 358-393.

[17] Christiano, Lawrence J., Mathias Trabandt and Karl Walentin (2011). "DSGE Models for Monetary Policy." In Handbook on Monetary Economics, Vol. 3A, edited by Benjamin M. Friedman and Michael Woodford. North-Holland, Chapter 7, pp. 285-367.

[18] Coeurdacier, Nicolas, Stéphane Guibaud and Keyu Jin (2012). "Credit Constraints and Growth in a Global Economy." CEPR Discussion Paper No. 9109.

[19] Dooley, Michael P., David Folkerts-Landau and Peter Garber (2004). "The US Current Account Deficit and Economic Development: Collateral for a Total Return Swap.” NBER Working Paper No. 10727.

[20] Gertler, Mark and Kenneth Rogoff (1990). "North-South Lending and Endogenous Domestic Capital Market Inefficiencies." Journal of Monetary Economics, 26, 245-266.

[21] Gilchrist, Simon and John C. Williams (2000). "Putty-clay and Investment: A Business Cycle Analysis." Journal of Political Economy, 108, 928-960. 
[22] Gourinchas, Pierre-Olivier and Olivier Jeanne (2013). "Capital Flows to Developing Countries: The Allocation Puzzle." Review of Economic Studies, 80, 1484-1515.

[23] Holmstrom, Bengt and Jean Tirole (2001). "LAPM: A Liquidity-Based Asset Pricing Model." The Journal of Finance, 56, 1837-1867.

[24] Huang, Yi (2011). "Can the Precautionary Motive Explain the Chinese Corporate Savings Puzzle? Evidence from the Liquid Assets Perspective." Mimeo, London Business School.

[25] Jain-Chandra, Sonali, Malhar Nabar and Nathan Porter (2011). "Corporate Savings and Rebalancing in Asia." In Rebalancing Growth in Asia: Economic Dimensions for China, edited by Vivek Arora and Roberto Cardarelli. International Monetary Fund, Chapter 2, pp. 29-48.

[26] Ju, Jiandong and Shang-Jin Wei (2006). "A Solution to Two Paradoxes of International Capital Flows." NBER Working Paper No. 12668.

[27] Ju, Jiandong and Shang-Jin Wei (2010). "Domestic Institutions and the Bypass Effect of Financial Globalization." American Economic Journal: Economic Policy, 2(4), 173-204.

[28] Juillard, Michel (1996). "Dynare: A Program for the Resolution and Simulation of Dynamic Models with Forward Variables through the Use of a Relaxation Algorithm." CEPREMAP Working Paper (Couverture Orange) No. 9602. 
[29] Karabarbounis, Loukas and Brent Neiman (2012). "Declining Labor Shares and the Global Rise of Corporate Savings." Chicago Booth Research Paper No. 12-17.

[30] Khurana, Inder K., Xiumin Martin and Raynolde Pereira (2006). "Financial Development and the Cash Flow Sensitivity of Cash." Journal of Financial and Quantitative Analysis, 41, 787-807.

[31] Kiribaeva, Koralai and Assaf Razin (2009). "Composition of International Capital Flows: A Survey." NBER Working Paper No. 15599.

[32] Kiyotaki, Nobuhiro and John Moore (2012). "Liquidity, Business Cycles, and Monetary Policy." NBER Working Paper No. 17934.

[33] Lane, Philip R. and Gian Maria Milesi-Ferretti (2007). "The External Wealth of Nations Mark II: Revised and Extended Estimates of Foreign Assets and Liabilities, 1970-2004." Journal of International Economics, 73, 223-250.

[34] Martin, Alberto and Filippo Taddei (2013). "International Capital Flows and Credit Market Imperfections: A Tale of Two Frictions." Journal of International Economics, 89, 441-452.

[35] Matsuyama, Kiminori (2007). "Credit Traps and Credit Cycles." American Economic Review, 97(1), 503-516.

[36] McLean, R. David (2011). "Share Issuance and Cash Savings." Journal of Financial Economics, 99, 693-715. 
[37] Mendoza, Enrique G., Vincenzo Quadrini and José-Víctor RíosRull (2007). "On the Welfare Implications of Financial Globalization without Financial Development." In NBER International Seminar on Macroeconomics 200\%, edited by Richard Clarida and Francesco Giavazzi. University of Chicago Press, pp. 283-312.

[38] Mendoza, Enrique G., Vincenzo Quadrini and José-Víctor Ríos-Rull (2009). "Financial Integration, Financial Development, and Global Imbalances." Journal of Political Economy, 117, 371-416.

[39] Sandri, Damiano (2014). "Growth and Capital Flows with Risky Entrepreneurship." American Economic Journal: Macroeconomics, 6(3), $102-123$.

[40] Song, Zheng, Kjetil Storesletten and Fabrizio Zilibotti (2011). "Growing Like China." American Economic Review, 101(1), 196-233.

[41] Woodford, Michael (1990). "Public Debt as Private Liquidit." American Economic Review, 80(2), 382-388. 

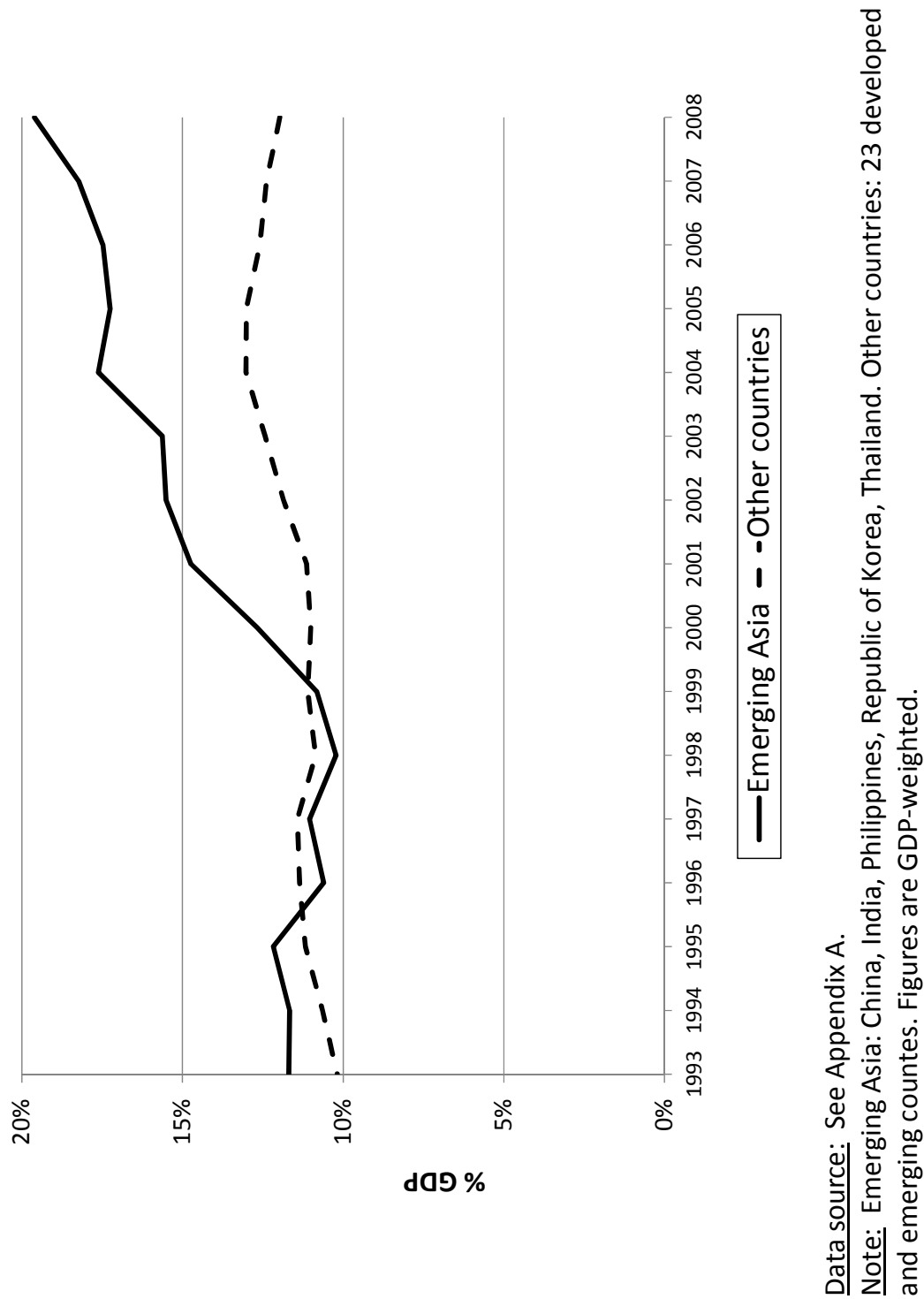


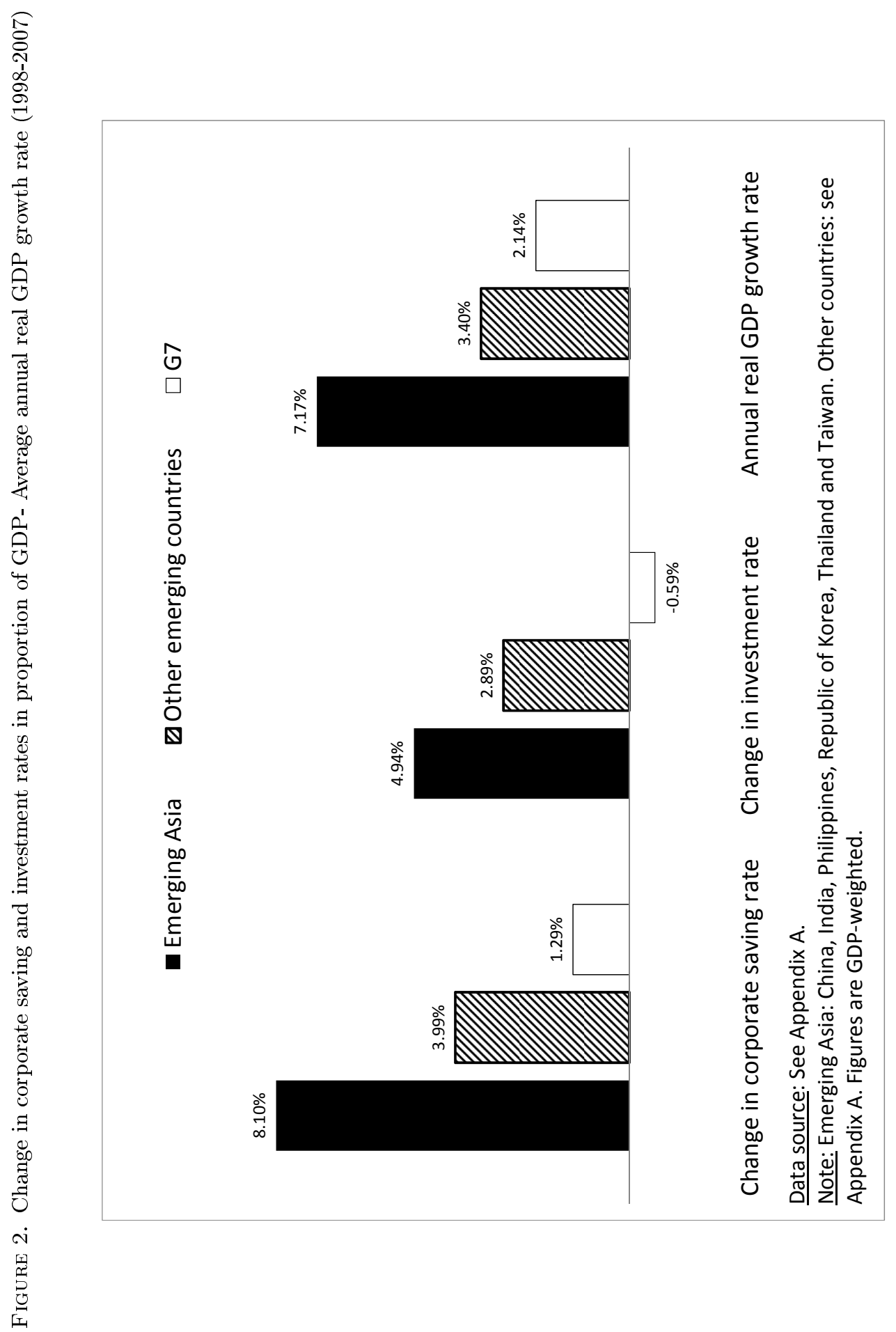




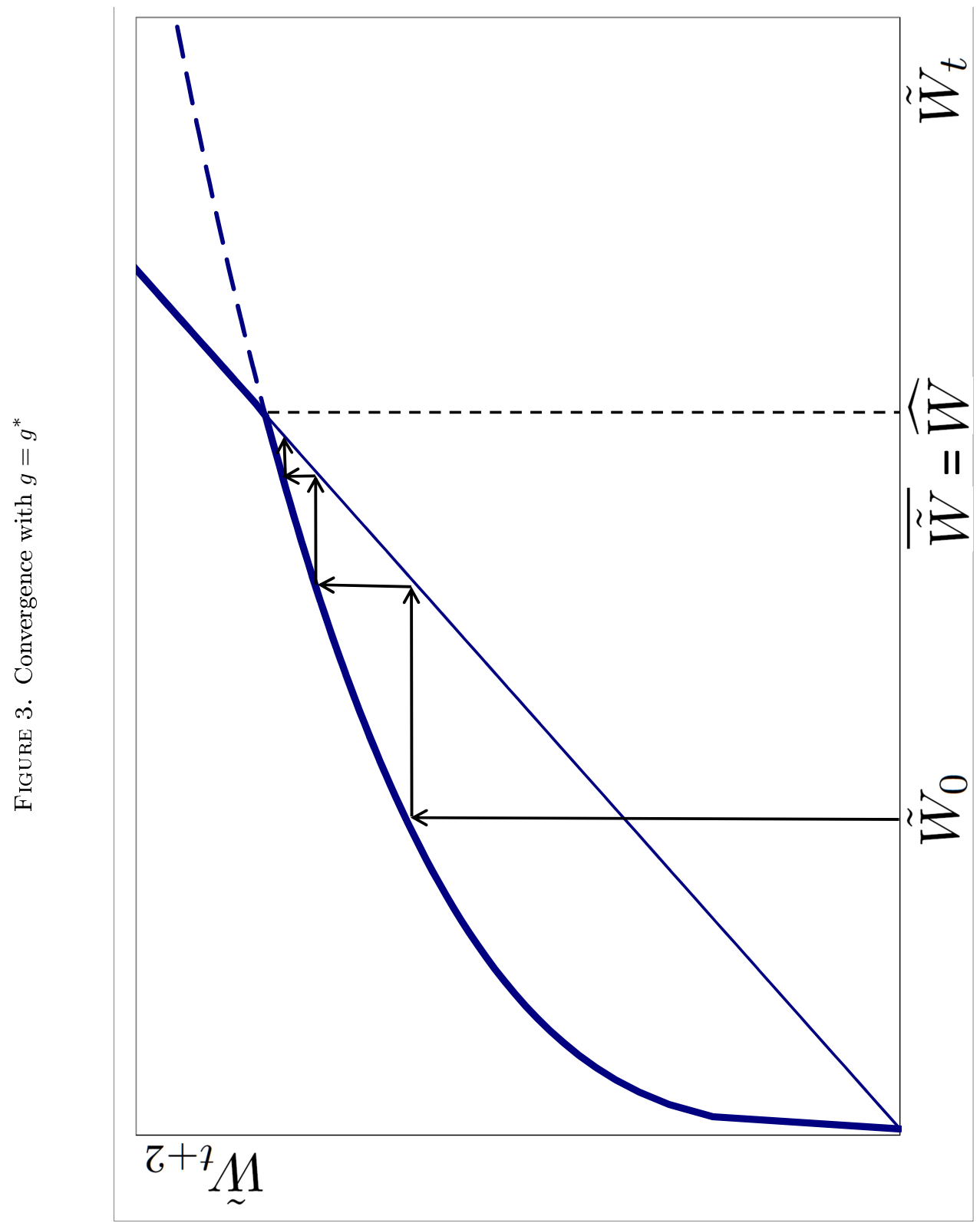


Figure 4. Convergence with $g=g^{*}$
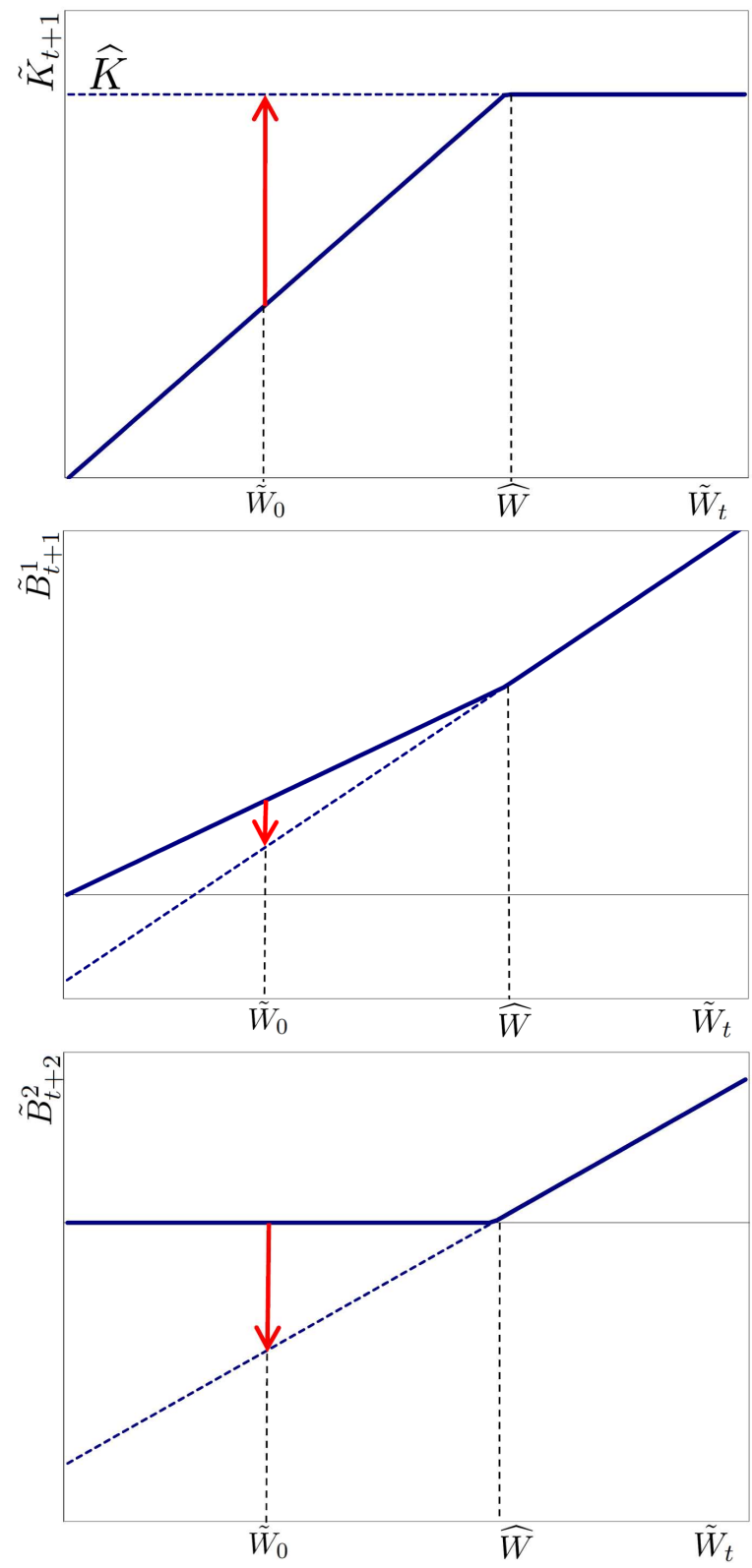


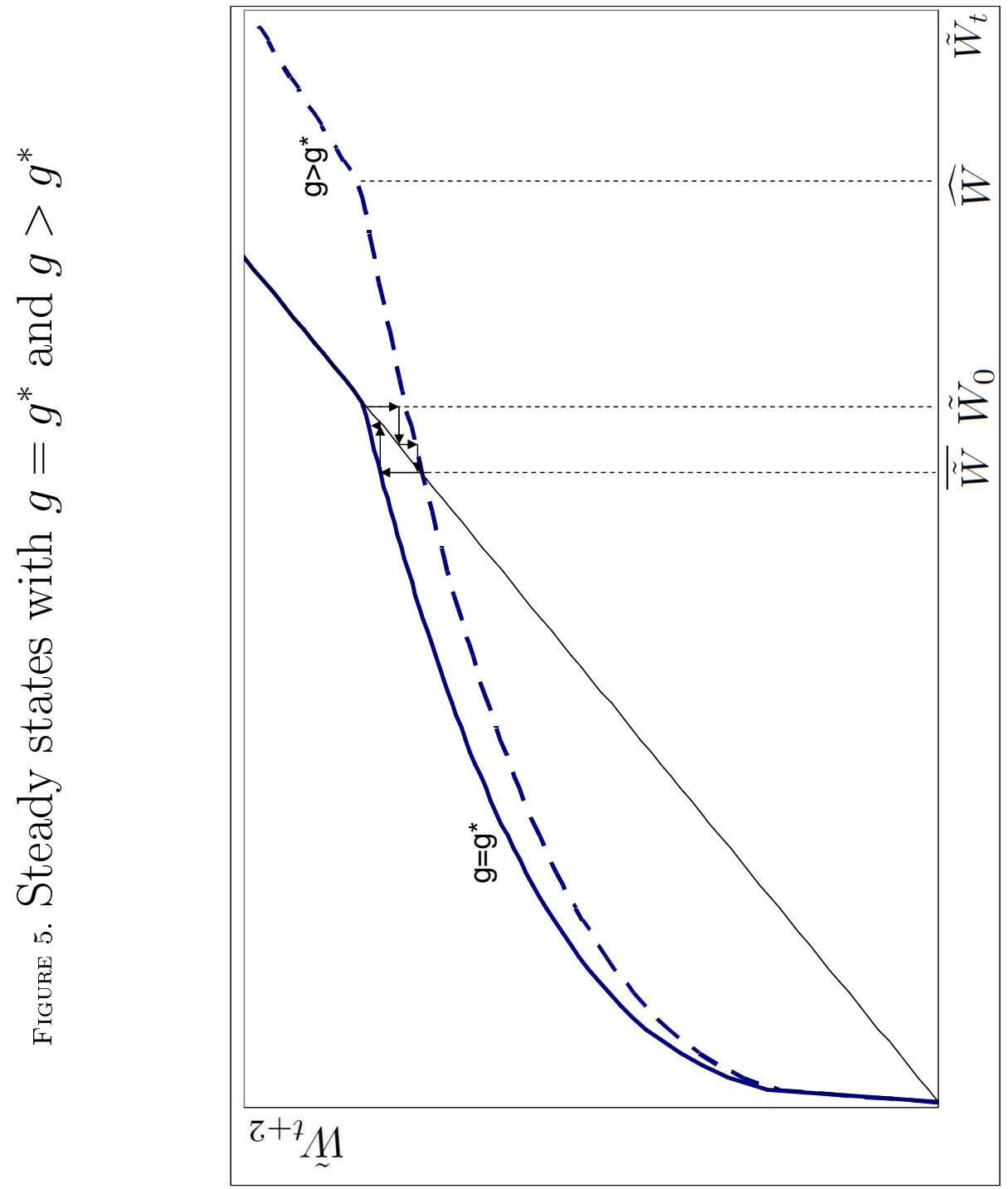




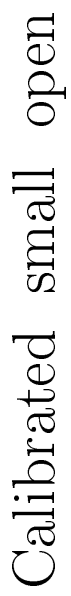
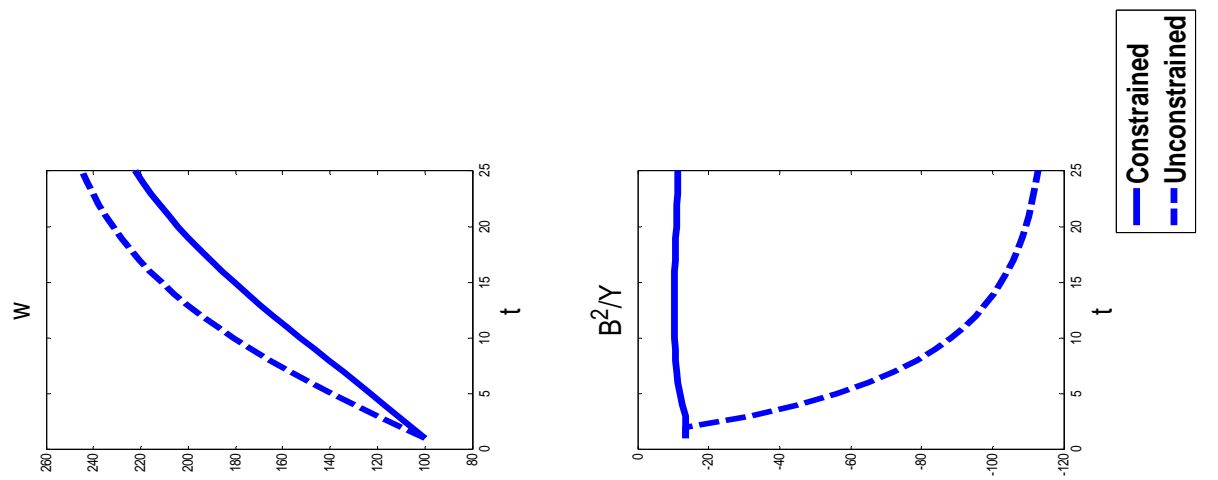

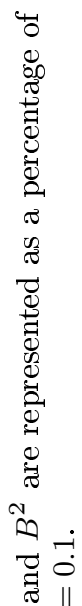
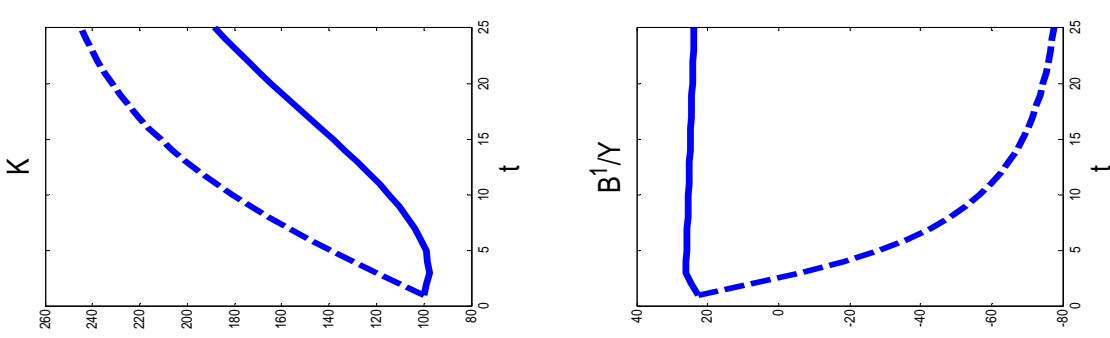

ำ

궁

芯

. 크
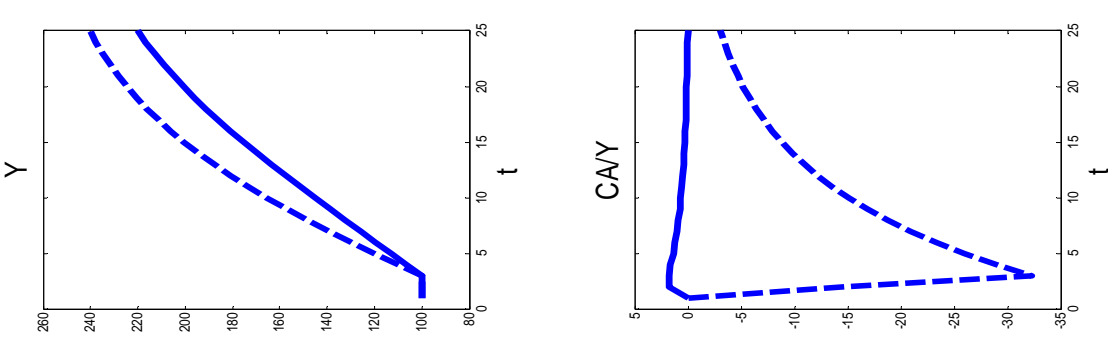

ช్
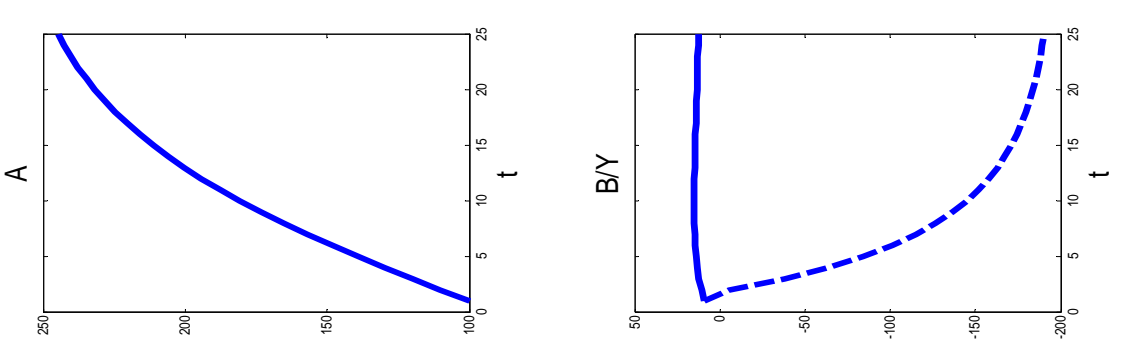

芆

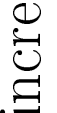

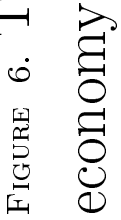

훙

乙 भ

ค่ं

닐

ही

突 11

ज 9

효용

证

ฮత

: *

용

임

$\infty_{\infty} \infty$

营 ?

政

8

$\approx$

ปิ

龸

证

过

๘ี

उ

귬

入

过是

षे

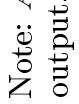




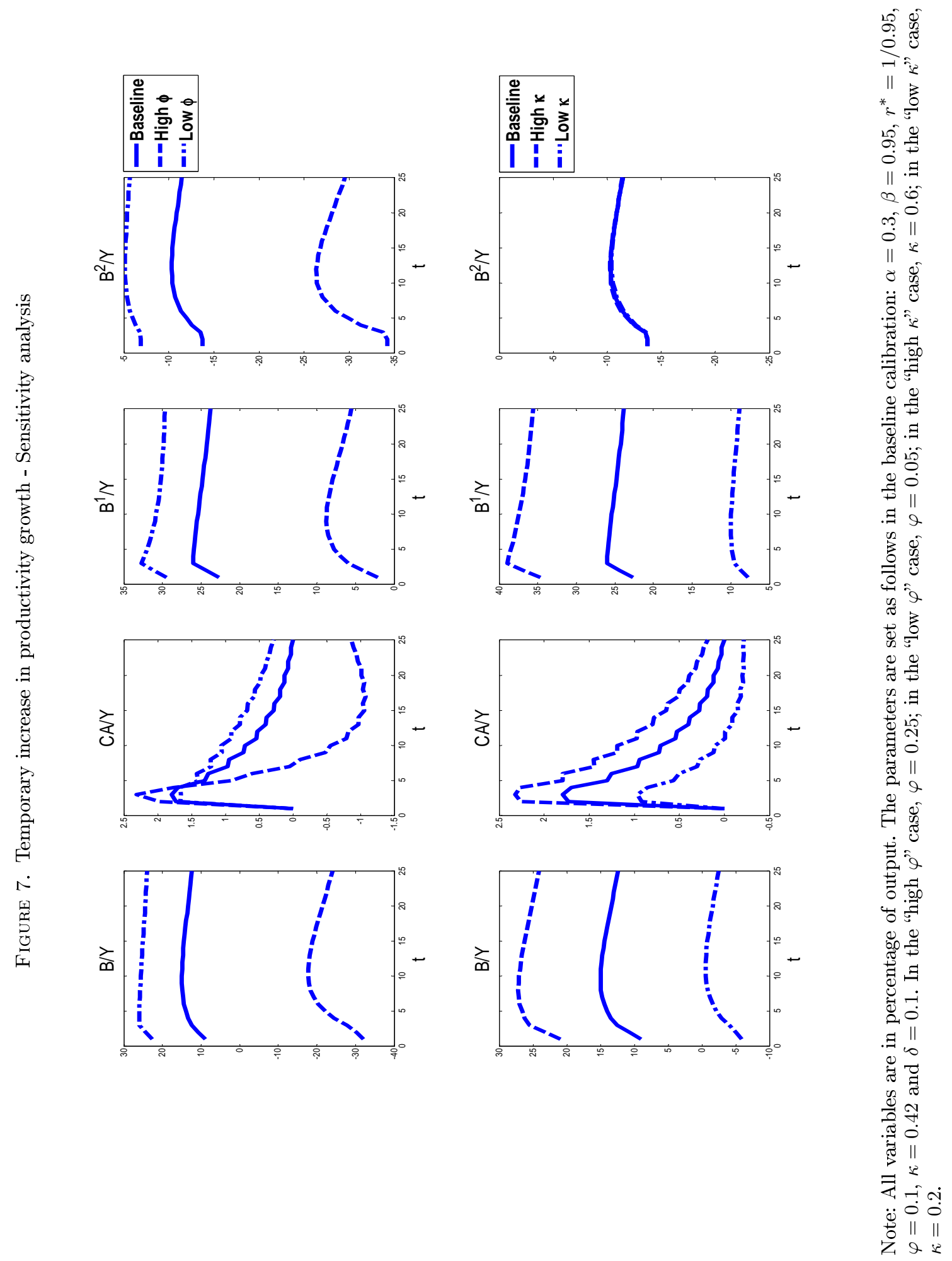



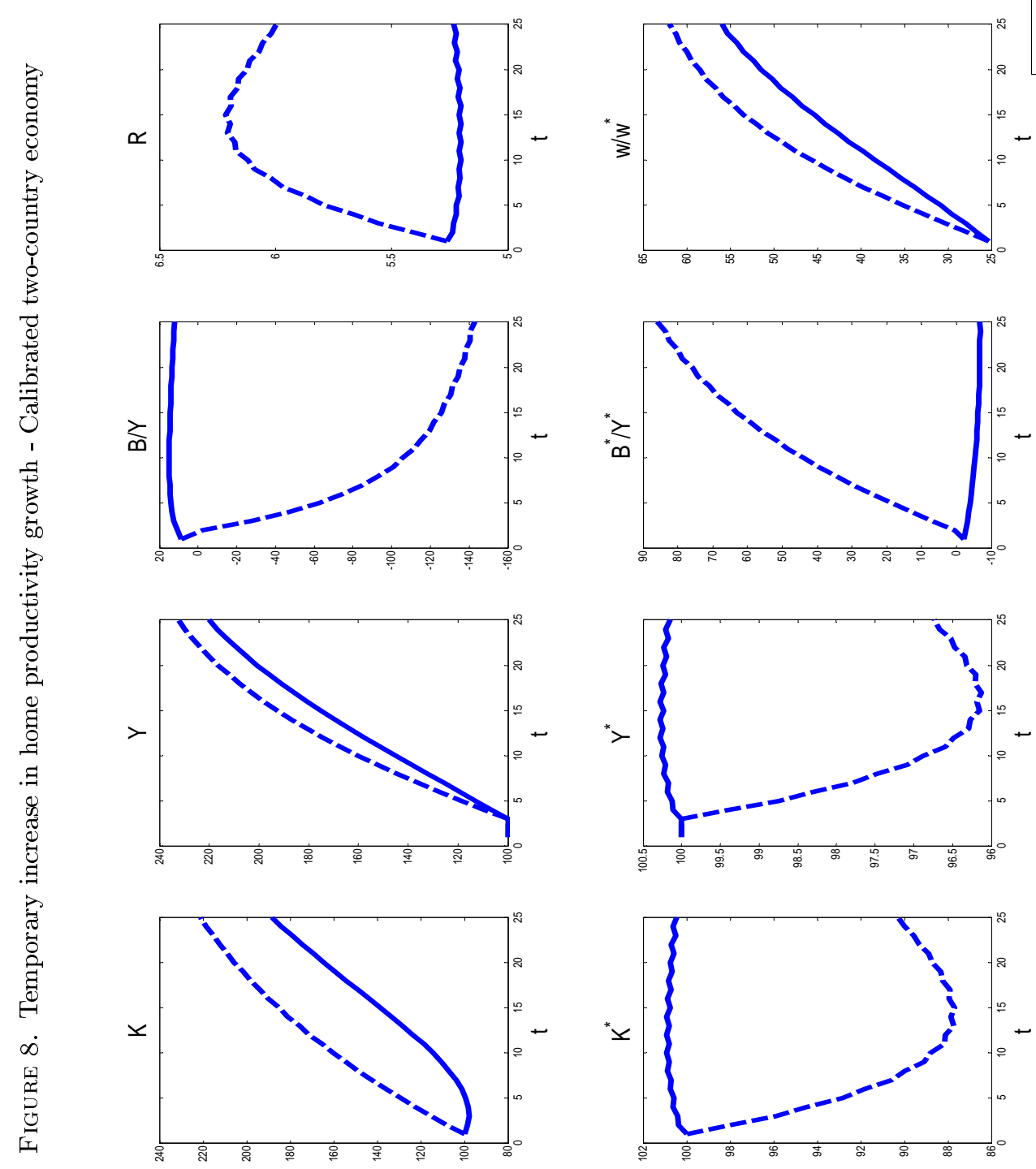

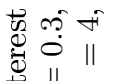

荚 